\title{
WestVirginiaUniversity
}

THE RESEARCH REPOSITORY @ WVU

Graduate Theses, Dissertations, and Problem Reports

2001

\section{Skeletal and dental changes with the acrylic splint Herbst appliance}

Jorge Clemente Casellas

West Virginia University

Follow this and additional works at: https://researchrepository.wvu.edu/etd

\section{Recommended Citation}

Casellas, Jorge Clemente, "Skeletal and dental changes with the acrylic splint Herbst appliance" (2001). Graduate Theses, Dissertations, and Problem Reports. 1245.

https://researchrepository.wvu.edu/etd/1245

This Thesis is protected by copyright and/or related rights. It has been brought to you by the The Research Repository @ WVU with permission from the rights-holder(s). You are free to use this Thesis in any way that is permitted by the copyright and related rights legislation that applies to your use. For other uses you must obtain permission from the rights-holder(s) directly, unless additional rights are indicated by a Creative Commons license in the record and/ or on the work itself. This Thesis has been accepted for inclusion in WVU Graduate Theses, Dissertations, and Problem Reports collection by an authorized administrator of The Research Repository @ WVU. For more information, please contact researchrepository@mail.wvu.edu. 


\title{
SKELETAL AND DENTAL CHANGES WITH THE ACRYLIC SPLINT HERBST APPLIANCE
}

\author{
By \\ Clemente Casellas D.D.S. \\ A THESIS \\ Submitted to the School of Dentistry \\ at \\ West Virginia University \\ in partial fulfillment of the requirements \\ for the degree of \\ Master of Science \\ in \\ Orthodontics

\begin{abstract}
Peter Ngan, D.M.D., Chair Jeffrey Gilmore, D.D.S., MS Marcia Gladwin, Ed.D.
\end{abstract} \\ Department of Orthodontics \\ Morgantown, West Virginia \\ 2001
}

Keywords: Graduate Programs, Functional Appliance, Acrylic Splint Herbst Therapy 


\section{ABSTRACT \\ Skeletal And Dental Changes With The Acrylic Splint Herbst Appliance}

\section{Clemente Casellas}

The skeletal and dental changes in response to acrylic splint Herbst appliance has not been studied extensively. The purpose of this study was to determine the amount of skeletal and dental cephalometric changes of Class II patients treated with acrylic splint Herbst appliance. The sample consisted of one experimental group and one control group. The experimental group consisted of lateral cephalometric radiographs of 22 patients who have been treated with acrylic splint Herbst from the files of the Department of Orthodontics, school of Dentistry, West Virginia University. The control group consisted of 22 cephalometric radiographs of Class II patients with no treatment, selected form the Case Western University Bolton-Brush Study, Cleveland Ohio. These patients were matched in sex, age and craniofacial morphology with the experimental group subjects. The cephalometric system described by Pancherz was used to determine the cephalometric changes. An analysis of variance (ANOVA) was used to determine statistical significant differences. Significant differences in skeletal and dental changes were found in patients treated with the acrylic splint Herbst when compared with the control group. An overjet correction of $4.6 \mathrm{~mm}$ and a molar relation correction of $5.6 \mathrm{~mm}$ was obtained when compared to the control group. The study showed that 58.7\% of the overjet correction was due to skeletal effects and 41.3\% to dentoalveolar adaptations. Therefore it can be concluded that the dentoalveolar effects were due mainly to changes in the lower incisors. Whereas the skeletal effects were due to a combination of maxillary and mandibular structure changes. 


\section{DEDICATION}

This thesis is dedicated to my wife and parents who have always encouraged and supported me.

A special thanks to the faculty, staff, and fellow residents who provided a wonderful environment in which to learn. 


\section{ACKNOWLEDGEMENTS}

Special thanks are extended to the following individuals:

Dr. Peter Ngan for serving as a chairman of my committee and for his invaluable guidance, encouragement, and editing throughout this project.

Dr. Marcia Gladwin for her skillful editing abilities and guidance.

Dr. Jeff Gilmore for his advice and encouragement throughout this thesis.

Dr. Erdrogan Gunel for the statistical analysis of the data. Case Western University Bolton-Brush Study (Cleveland, Ohio) for providing the records for this study. 
TABLE OF CONTENTS

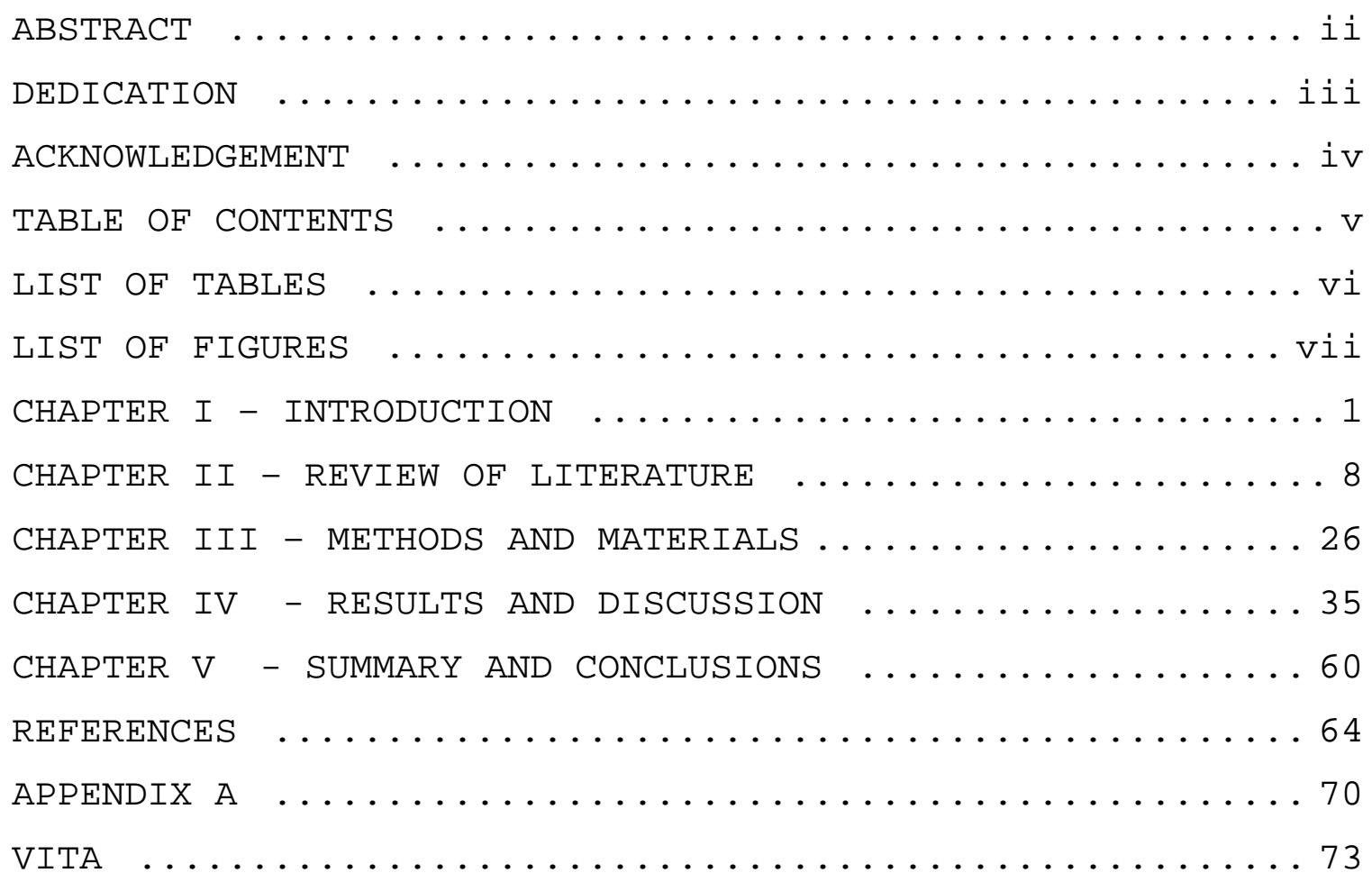




\section{LIST OF TABLES}

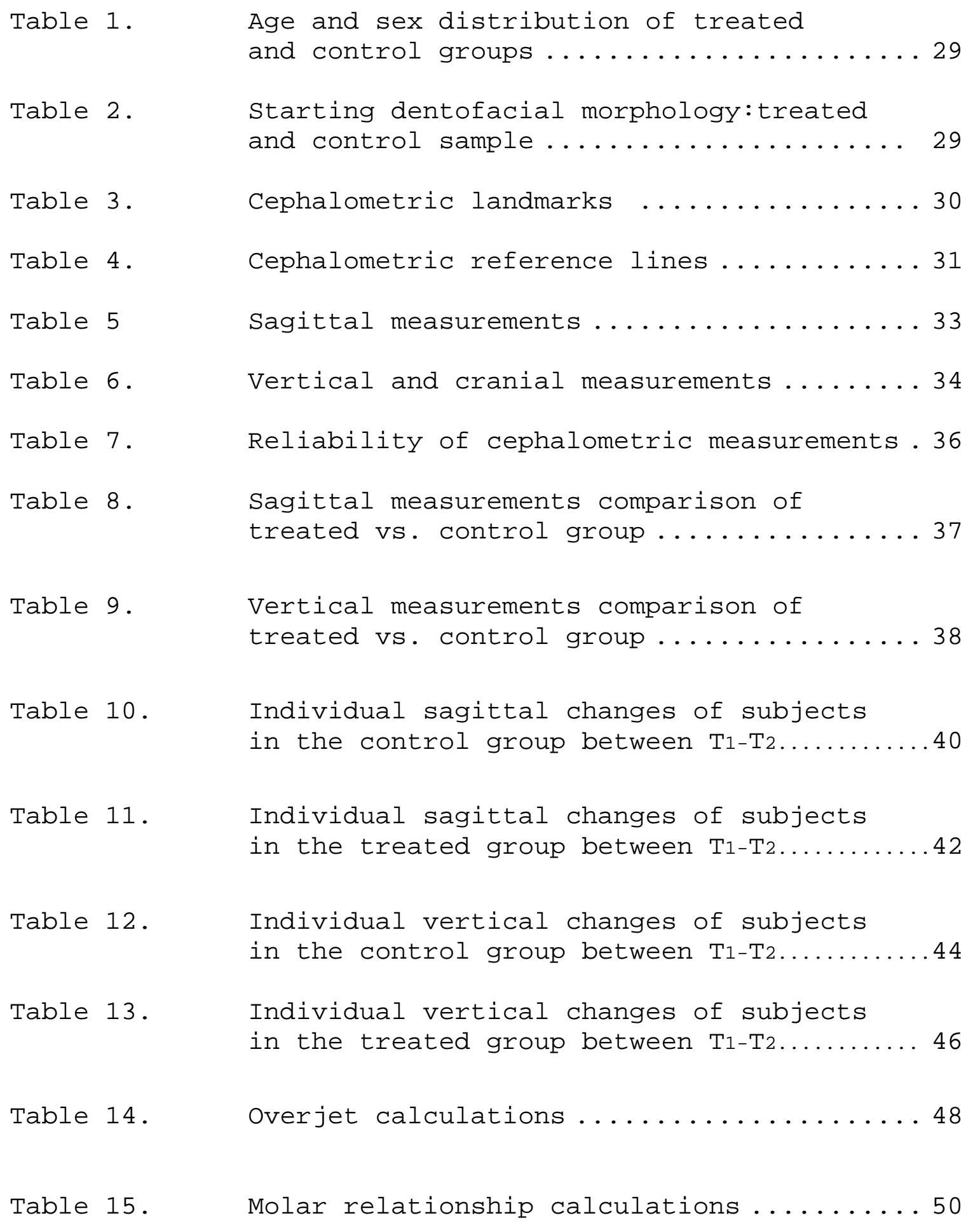




\section{LIST OF FIGURES}

Figure 1. Acrylic Splint Herbst Appliance.......... 27

Figure 2. The skeletal and dental cephalometric landmarks and reference line ...............32

Figure 3. Skeletal and dental contributions to the overjet correction ............... 47

Figure 4. Skeletal and dental contributions to the molar relationship correction .........4 49 


\section{CHAPTER I}

\section{INTRODUCTION}

Class II malocclusion with mandibular deficiency can be treated using fixed or removable functional appliances. The Herbst appliance is a fixed functional appliance that has been shown to be effective in the treatment of class II malocclusion. The original design of the Herbst appliance has orthodontic bands fitted on the premolars and molars. The bonded Herbst appliance was first proposed by Howe and McNamara(1982) and later evolved into the acrylic splint Herbst appliance ${ }^{1}$. The skeletal and dental changes associated with the banded Herbst appliance are well documented in the literature. However, there is a scarcity of literature on the changes associated with the acrylic splint Herbst appliance.

The aim of this study is to determine the amount of skeletal and dental cephalometric changes of Class II patients treated with acrylic splint Herbst appliance.

\section{STATEMENT OF THE PROBLEM}

The skeletal and dental changes in response to acrylic splint Herbst appliance has not been studied extensively. The objective of this study is to determine the cephalometric skeletal and dental changes of a group of Class II patients treated with the acrylic splint Herbst appliance. 


\title{
SIGNIFICANCE OF THE PROBLEM
}

\begin{abstract}
Fixed and banded Herbst appliance was used extensively in Europe for treatment of Class II division 1 malocclusion with mandibular deficiency. The acrylic splint Herbst appliance was introduced by McNamara in 1988 to provide additional anchorage for Class II correction ${ }^{1}$. The bonded appliance has the advantage of providing better anchorage by splinting the maxillary dentition together. However, it also suffers the disadvantage of having a removable lower member that requires patient compliance.
\end{abstract}

Results of this study will provide information on the skeletal and dental contribution to correction of Class II malocclusion using the acrylic splint Herbst appliance. Data can also be used in future studies to compare with those published using the fixed banded Herbst appliances. Clinicians can then decide on the advantage of using such appliance in the treatment of developing Class II malocclusion. 


\section{HYPOTHESIS}

Two hypothesis from the basis study. They are:

1. There are no significant skeletal changes using cephalometric linear and angular measurements in patients treated with the acrylic splint Herbst appliance when compare with the control group.

2. There are no significant dental changes using cephalometric linear and angular measurements in patients treated with the acrylic splint Herbst appliance when compare with the control group.

\section{DEFINITIONS OF TERMS}

1. Maxillary expansion: Separation of the two halves of the maxilla achieved in the growing individual with the use of an orthopedic expansion device. ${ }^{2}$

2. Brachycephalic: Descriptive term utilized to describe the shape of an individual's head as being more round, horizontally shorter, and broader. ${ }^{3}$

3. Dolichocephalic: Descriptive term which describes the 
shape of an individual's head as being horizontally long long and relatively narrow. ${ }^{3}$

4. Mesocephalic: Shape of an individual's head, which is considered as being median between brachycephalic and dolichocephalic. ${ }^{3}$

5. Class II Malocclusion: That relationship in which the buccal groove of the mandibular first permanent molar articulates posteriorly to the mesiobuccal cusp of the maxillary first permanent molar. In other words, this represents a mesial relationship of the upper first molar to the lower first molar. ${ }^{3}$

6. Skeletal Class II Malocclusion: Skeletal relationship in which either the mandible is retrognathic, the maxilla is prognathic, or a combination of the two. ${ }^{3}$

7. Remodeling: A mechanically controlled activity that promotes tissue turnover throughout life. ${ }^{4}$

\section{ASSUMPTIONS}

This research is based upon three assumptions: 
The lateral cephalograms are taken with the teeth in centric occlusion copromises the first assumption. It may be assumed that growth modification occurs in patients treated with the Herbst appliance. ${ }^{5,6,7}$

Condylar remodeling take place in patients treated with the Herbst appliance comprises the third assumption. ${ }^{8}$

\section{LIMITATIONS}

The following limitations may apply to the overall study:

1. This is a retrospective study with a group of patients selected from the files in the Department of Othodontics, West Virginia University. The samples in the treatment and control groups are not selected at random.

2. The sample size was limited to the availability of patients and complete records.

3. The patient population has been selected from two different sources. (West Virginia University and Case Western University/ Bolton-Brush Study Center)

、

\section{DELIMITATIONS}

The following delimitations may apply to the overall study. 
1. Inclusion criteria for patient selection in the experimental group:

A) Female and male patients in mixed and early permanent dentitions that were diagnosed with Class II malocclusion with mandibular deficiency.

B) Patients that were treated with acrylic splint Herbst appliance with bonded upper member and removable lower member.

C) No previous orthodontic treatment.

D) The time between the pre and post-treatment cephalometric radiograph is limited to 12 months or less.

E) Availability of post-treatment cephalometric radiographs.

2. Exclusion criteria for patient selection in the experimental group: 
A) Patients that are not cooperative in wearing the lower member of the Herbst appliance will be excluded from the study

B) Patients with cephalograms taken more than 6 months after removal of the appliance will be excluded from the study

3. Criteria for patient selection for the control group is limited to:

A) Female and male patients in mixed and early permanent dentitions with mandibular deficiency.

B) Patients that match the skeletal morphology of the experimental group in terms of angular and linear cephalometric measurements. 


\section{CHAPTER II}

\section{REVIEW OF THE LITERATURE}

\section{INCIDENCE}

Class II malocclusion is a commonly observed clinical

problem, occurring in about one third of the United states population ${ }^{9,10,11,12}$. This classification of malocclusion seems to be more prevalent in individuals of Northern European ancestry (30\%-40\%) than in other racial and ethnic groups (14\%-18\% in blacks). Approximately eight to ten percent of the overall population have an overjet greater than six mm.

\section{ETIOLOGY}

The etiology of Class II malocclusion is multifactorial in nature. Skeletal orthodontic problems arise mainly as a result of an inherited pattern. In the United States, Class II malocclusion is due mainly to mandibular deficiency ${ }^{3}$. Only a few types of Class II malocclusion are caused by specific interference with growth. There is little reason to believe that any significant number are the result of functional causes alone. This is not to say that functional alterations in equilibrium can't accentuate class II tendencies when they are present. The more severe cases probably fall into this category of inherited tendencies made worse by environmental effects ${ }^{3}$ 
COMPONENTS OF CLASS II MALOCCLUSION

According to Angle's classification, class II
malocclusion occurs when the lower molar is distally
positioned relative to the upper molar with the line of
occlusion not specified. Angle based his classification system
solely on the position of the permanent upper first molars ${ }^{3}$.
In reality, there can be numerous combinations of skeletal
and dentoalveolar class II malocclusions.

The different components of the Class II malocclusion have been described by Henry ${ }^{13}$, Moyers et al ${ }^{14}$ and McNamara ${ }^{15}$. Cross-sectional studies ${ }^{16-27}$ have shown that components of Class II malocclusion can be categorized into four main groups: anterior position of the maxilla, anterior position of the maxillary dentition, mandibular skeletal retrusion in absolute size or relative position, and excessive or deficient vertical development.

\section{SKELETAL CLASS II GROWTH}

Orientation of the facial bones can contribute to the class I skeletal malocclusion. The bones in the cranial facial complex can be divided into several segments including the 
anterior and posterior cranial base, nasomaxillary complex and the mandible $e^{28}$.

Cranial Base: The primary growth in the cranium is through deposition on the outer cortex/resorption of the inner cortex and the spheno-occipital synchondrosis. The sphenooccipital synchondrosis is a major growth center and enlarges by endochondral growth. It also provides a bi-directional growth direction, which is described as a pressure adaptive mechanism that causes a displacement of bones ${ }^{28}$.

Although Enlow states that the cranial base may lead to a downward and backward deflection of the mandible, creating a tendency towards a Class II malocclusion, no significant differences were found in a longitudinal study comparing the cranial base measurements between Class I and Class II individuals ${ }^{29}$.

\section{Nasomaxillary Complex and Mandible:}

The growth of the maxilla occurs via bony apposition at the sutures between the cranium and the maxilla. The maxilla is displaced downward and forward away from the cranium. Exorbitant growth in either direction or an overall enlargement in the anterior posterior dimension may lead to a Class II skeletal pattern ${ }^{28}$. In a cephalometric analysis 
McNamara ${ }^{15}$ found that in Class II individuals, the position of the maxilla(SNA and A point perpendicular) is normal in majority of the cases. In other cases, the maxilla tended to be retrusive more than protrusive. Although a longitudinal study by Ngan et al, show no significant differences between Class I and Class II in the SNA angle, the last one tended to increase in Class I female subjects and decrease in Class II female subjects during growth spurt ${ }^{29}$.

Mandible:

The mandible grows by deposition and resorption (remodeling). The predominant vectors (direction and magnitude) of growth are posterior and superior. Thus, the condyle grows directly toward its articular contact in the glenoid fossa of the cranial floor. As this take place, the whole mandible is moved forward and downward by the same amount that it grows upward and backward (displacement). The direction of growth by new bone additions at the condyle and the direction of displacement are opposite to each other ${ }^{29}$

The growth of the mandible may contribute to a class II skeletal pattern by having a short corpus length, small ramus width, reduced ramus height or small gonial angle. 
Canted occlusal plane can also play a role in the mandibular position. An occlusal plane that is canted inferiorly in the anterior will to a more retrognathically positioned mandible $e^{29}$.

Bjork ${ }^{30}$ demonstrated several types of rotation in the mandible which can be used to predict different growth patterns of the mandible. They are defined as follows:

Type I: Axis of rotation is the condyle and the growth is upward. Normally seen in Class II division 2 cases.

Type II: Axis of rotation at the incisal edge causing downward rotational growth of the ramus and this leads to an increase in the posterior face height and shallow mandibular plane(Class II division 2).

Type III: Axis of rotation is a fulcrum point on the posterior teeth and this leads to a downward rotation of the posterior mandible and superior rotation of the anterior region. Increased posterior face height and decreased anterior face height are some of the features seen in Class II division 2 .

Type IV: Axis of rotation is the center of the condyle. Rotation is down and backward. This leads to an increased 
anterior face height which may be caused by bite opening devices(seen in prolonged intubation of young children) leading to a Class II division 1 pattern.

Type V: Axis of rotation is a fulcrum point in the posterior dentition and the rotation of the mandible is down and back leading to increased anterior face height and a retrognathic profile seen in Class II division 1 patterns.

\section{DIAGNOSIS OF CLASS II MALOCCLUSIONS}

A simplified method of evaluating patients by components according to the different planes of space assists in diagnosing the underlying cause of a Class II malocclusion ${ }^{31}$.

\section{ANTEROPOSTERIOR COMPONENTS}

Of critical importance is the soft tissue profile, particularly the nasolabial angle and the cant(slope) of the upper lip. Ideally, the nasolabial angle should be $102^{\circ} \pm 8^{\circ}$ in both boys and girls of Northern European ancestry (adults: $101^{\circ} \pm 12^{\circ}$ in males and $107.5^{\circ} \pm 7.5^{\circ}$ in females). In addition, the cant of the upper lip should be angled slightly in an anterioinferior direction $\left(8^{\circ} \pm 8^{\circ}\right.$ in white males; $14^{\circ} \pm 8^{\circ}$ in white females relative to the nasion perpendicular ${ }^{32}$ 
The anteroposterior position of the bony maxilla is analyzed cephalometricaly. Two cephalometric measures of anteroposterior maxillary position are nasion perpendicular to Point $A^{33}$ and Sella-Nasion Point $A$ (SNA) angle ${ }^{34,35}$. The position of the maxilla is normal in the majority of class II individuals and in those that the position of the maxilla is abnormal, the maxilla tends to be retrusive. Patients showing a long lower anterior facial height and steep mandibular plane angle often have both a maxilla and mandible that are retruded relative to cranial base structures.

When estimating the position of the upper incisors relative to the maxilla, the distance from the facial surface of the upper incisor to a vertical line drawn perpendicular to the Frankfort horizontal plane extended through Point $\mathrm{A}^{33}$ is recommended. In a well-balanced face, this measurement should be 4 to $6 \mathrm{~mm}^{33,36,2}$. In Class II patients ${ }^{15}$, almost half have a normally positioned upper incisor, 30\% have a retrusive position and $20 \%$ have a protrusive position. A retruded incisor position represents an interference for Class II correction, especially when it involves the forward repositioning of the mandible(e.g., functional appliance therapy, mandibular advancement surgery) or retraction of the maxilla(e.g. extraoral traction, Le Fort I osteotomy). 
The distance from the tip of the lower incisor to the APogonion line 37,38 can be used to determine the antero-posterior position of the lower incisor in relation to basal bone structures. Approximately two thirds of the Class II malocclusion have a normally positioned lower incisor.

To evaluate the mandibular skeletal position relative to the cranial base and cranial structures, two measurements can be used: Pogonion to the nasion perpendicular ${ }^{33}$ and SellaNasion-B point(SNB) angle $e^{34,35}$. These measures indicate that a deficiency in the anterior-posterior position of the mandible is about $60 \%$ in the Class II malocclusion.

\section{VERTICAL COMPONENTS}

Although Class II malocclusion usually is perceived as a sagittal problem, the vertical dimension of the patient also must be considered. Especially since this dimension may either conceal or intensify the clinical appearance of the malocclusion. ${ }^{38-39}$

A decreased in vertical dimension causes the mandible to rotate upward and forward. A patient with a short lower anterior facial height can camouflage a mandible that is structurally small relative to the midface. These patients 
typically have a low mandibular plane angle, a deep overbite with a strong chin point, and either retruded or flared upper incisors.

A patient with an increased lower anterior facial height often is characterized by a retruded mandible (and occasionally the maxilla as well), a poorly defined chin point with a hyperactive mentalis muscle("golf-ball" chin), and a tendency toward or an anterior open bite. A bump on the nasal contour ("dorsal hump") often is observed clinically in patients with both maxillary and mandibular skeletal retrusion and a Class II malocclusion.

To evaluate the vertical dimension, two measurements can be utilized ${ }^{15}$ The mandible plane angle (MP-SN, MP-FH) and lower anterior facial height (anterior nasal spine to menton).

Although Class II patients most frequently have a neutral vertical dimension, about one third have excessive vertical development. Decreased vertical development is less common, occurring only in about $10 \%$ of the cases.

\section{TRANSVERSE COMPONENTS}

A dimension often overlooked in the evaluation of the Class II patient is the transverse relationship of the maxilla 
to the mandible. Most Class II patients appear to have a normal relationship of the buccal segments when the patient is in centric occlusion. Tollaro et al, ${ }^{40}$ however, have shown that an underlying transverse discrepancy of three to five mm exists in dental arches with Class II malocclusion and seemingly normal buccal relationships. This underlying transverse discrepancy can be unmasked clinically by having the patient posture the mandible in an anterior position so that the canines are positioned in a Class I relationship. More significant transverse discrepancies are evidenced by unilateral or bilateral posterior crossbites in centric occlusion.

Studies by Baccetti et $a 1^{41}$, Arya et $a 1^{42}$, and Bishara et $a^{43}$, indicate that the Class II occlusal relationship tends to be self-perpetuating, and continues to be associated with a constricted transverse occlusal relationship.

Spillane ${ }^{44}$ and McNamara ${ }^{2}$ have recommended that in mild to moderate Class II patients with reasonably well balanced faces, orthopedic expansion of the maxilla through rapid maxillary expansion during the early mixed dentition is advisable. Not only will it create some additional arch space to allow for the eruption of the permanent incisors, but it 
may also spontaneously correct the occlusal relationship by encouraging a transient forward mandibular posturing, in that the patient occludes more comfortably in a slight anterior position.

\section{TREATMENT OF CLASS II MALOCCLUSION}

Excluding surgical reposition of the jaws, there are four major possibilities for Class II correction:

I. Differential anteroposterior movement of the upper and lower posterior teeth as extraction spaces are closed.

II. Distal movement of maxillary posterior teeth.

III. Differential anteroposterior movement of all the teeth under the influence of Class II elastics.

IV. Differential growth of the jaws, guided by extraoral force or a functional appliance ${ }^{3}$.

Although these approaches are not mutually exclusive and a combination is almost always used in treatment, the scope of this study is to focus on the last one. 
I. There are two reasons for extracting teeth in the treatment of Class II malocclusion: (1) to provide space to align crowded incisors without creating excessive protrusion and (2) to allow camouflage of moderate class II jaw relationships when correction by growth is not possible. Camouflage by extraction of upper first premolars and lower second premolars is a deceptively attractive solution to Class I problems although should be adopted only in specific cases.

II. Class II nonextraction treatment, which commonly includes distal movement of the maxillary molars to correct the molar relationship, most often can be successful when treatment is started in the late mixed dentition stage of development. At least two factors contribute to this success. One is that the molars can be distalized routinely at this age. The second is that the "E" space is available and can be used either to help correct the molar relationship or to resolve any crowding that may exist. ${ }^{45}$

III. Molar correction with Class II elastics, without extraction spaces, is produced largely by mesial movement of the mandibular arch, with a small amount of distal positioning of the maxillary arch. Large amount of force is usually required (approximately $300 \mathrm{gm}$ per side) to displace one arch relative to the other when both are stabilized with 
rectangular archwires. It is important to keep in mind that Class II elastics produce not only anteroposterior and transverse effects but also a vertical force. Class II are therefore contraindicated in nongrowing patients who can not tolerate some downward and backward rotation of the mandible This is why Class II elastics are usually indicated for 3 to 4 months at the completion of treatment rather than using them for 9 to 12 months as the major method of correcting a class II malocclusion.

\section{FUNCTIONAL APPLIANCE HERBST THERAPY}

The different timing of skeletal growth in males and

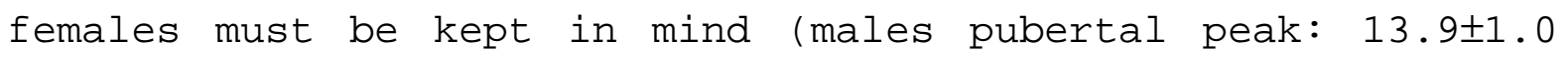
yrs. and females pubertal peak: $11.7 \pm 1.0$ yrs.) when using extraoral force or functional appliances to influence jaw growth ${ }^{46}$. A favorable response of growth modification includes both restrain of maxillary growth and differential mandibular growth. Although the main purpose is to modify growth, some tooth movement in all three planes of space inevitably accompanies it.

Among the various types of orthopedic and functional appliances available today, the Herbst appliance is thought to be an effective device to correct Class II malocclusions 
In contrast to the removable functional appliances such as the activators, bionators, or Frankel appliance, the fixed Herbst appliance has several advantages ${ }^{47}$ it works 24 hours a day, no cooperation by the patient is required, and (3) active treatment time is short (6 to 12 months).

During the last 20 years, a number of clinical studies have evaluated the effects of the various types of Herbst appliances on the craniofacial skeleton. The banded type of Herbst appliance was developed by Emil Herbst in 1905 and was reintroduced by Pancherz in 1979. Both skeletal and dentoalveolar effects have been documented, regardless of the method of attachment of the Herbst mechanism to the dental arches $\left[\right.$ e.g., banded ${ }^{47}{ }^{5}$, cast splint ${ }^{48}$, acrylic splint, ${ }^{49,50}$ and stainless steel crowns ${ }^{51,52}$.

In 1988 McNamara and Howe described the current design of the acrylic splint Herbst appliance, with occlusal coverage extending posteriorly from the canines to the first molars in the maxillary arch and full occlusal coverage in the mandibular arch. The maxillary splint is either removable or bonded, whereas the mandibular splint always is removable.

Most previous investigators have reported only limited effects of the Herbst appliance on the maxillary complex. When 
change in maxillary position (SNA) is evaluated, the forward growth of maxilla relative to nasion is slightly less in comparison with untreated controls ${ }^{47,5,50,53}$.

Increases in the length of the mandible, ranging from $1.3 \mathrm{~mm}$ to $3.5 \mathrm{~mm}$, have been documented in previous clinical studies of the Herbst appliance in comparison with untreated controls. Pancherz ${ }^{47,54}$ found that the average increase in mandibular length of 10 treated growing patients exceeded that of 10 untreated growing subjects by $2.2 \mathrm{~mm}$ over a 6-month period. A subsequent study by Pancherz ${ }^{5}$ also showed an additional $2.0 \mathrm{~mm}$ of length increase. In an investigation of Headgear-Herbst treatment on a group of patients with severe Class II malocclusions in the early mixed dentition, Wieslander ${ }^{48}$ reported that within a 5 month interval, mandibular length increased $2.0 \mathrm{~mm}$ more in a treated group than in an untreated control group. Valant and Sinclair 53 reported additional mandibular growth of $1.3 \mathrm{~mm}$ in a 10 -month treatment period. McNamara et $a^{49}$ reported an average of 2.7 mm more growth than in an untreated group, whereas Windmiller ${ }^{50}$ reported an additional 3.5-mm of mandibular length increase. Remodeling of the temporomandibular joint (TMJ) has been described to occur both within the glenoid fossa and at the mandibular condyles, with new bone formation occurring on the 
roof of the fossa and on the posterior aspect of the condylar head $^{55,8}$. However Croft et al, ${ }^{7}$ recently suggested that glenoid fossa displacement does not contribute in a clinically significant way to Class II correction. They also demonstrated with tomograms a tendency for the condyle to be slightly forward $(0.2 \mathrm{~mm})$ at the end of treatment and then to fall back after treatment. Instead they found a significant redirection of condylar growth.

Previous studies have shown that Herbst appliance treatment typically has a bite opening effect. Pancherz ${ }^{47,5}$ observed an increase in lower anterior facial height produced by the banded Herbst appliance. In the investigation of treatment effects with the acrylic-splint Herbst, Both McNamara et $\mathrm{al}^{49}$ and Windmiller ${ }^{50}$ reported a significant increase in lower anterior facial height in the treatment groups. These studies did not show significant treatment effect on the mandibular plane, presumably because of an increase in ramus height posteriorly ${ }^{49,50}$. In a study of vertical changes produced by different types of Herbst appliances, Schiavoni et $a 1^{57}$ found the banded type as used by Panceherz did not modify the vertical growth pattern significantly, whereas the acrylic-splint type allowed an upward and forward rotation of the mandible. 
In the dentoalveolar region, the Herbst bite jumping mechanism produces a posteriorly-directed force on the upper teeth and an anteriorly directed force on the lower teeth, resulting in distal tooth movement in the maxillary buccal segments and mesial tooth movements in the mandible. The mandibular incisors have been shown to procline during Herbst treatment ${ }^{47,5,53,56}$. An Analysis of vertical dentoalveolar changes revealed that the upper first molars and lower incisors are inhibited from erupting during treatment 5,49,53, whereas the eruption of lower first molars is not affected significantly $y^{49,50,53}$.

In summary the overjet and the class II molar correction are a result of the following maxillary and mandibular skeletal and dental changes ${ }^{58}$ :

- Inhibition of maxillary growth

- Enhance of mandibular growth

- Distalization of maxillary buccal segments

- Proclination of mandibular incisors

Without proper retention, however, this effect is of a temporary nature. Herbst treatment is especially indicated in the permanent dentition at or just after the pubertal peak of growth. Mixed dentition treatment is not recommended, as a 
stable cuspal interdigitation after therapy is difficult to achieve and relapses are prone to occur. In the nongrowing patient, the appliance should be used with great caution. ${ }^{58}$

The existing scientific data with respect to the short and long term effects of the Herbst appliance on the occlusion and on the maxillo/mandibular complex was analyzed by Pancherz, 6 months and 3.1 years posttreatment.

During the first posttreatment period of 6 months, effective condylar growth recovered with respect to both the direction and the amount of changes. During the second posttreatment period of 2.5 years, effective condylar growth was "normal." The corresponding chin position changes during the different examination periods were a mirror image of "effective condylar growth" (a summation of condylar remodeling, glenoid fossa remodeling, and condylar position changes within the fossa)when any mandibular autorotation occurred. In those cases with anterior mandibular autorotation, relatively more forward directed chin position changes resulted and in cases with posterior mandibular autorotation, relatively more backward directed chin position changes resulted. 


\section{CHAPTER III}

\section{METHODS AND MATERIALS}

\section{APPLIANCE DESIGN}

The acrylic splint Herbst Appliance is composed of a wire framework, over which has been adapted 2.5-3.0 mm thick splint Biocryl. The posterior teeth are covered from the canines through the first molars in the maxillary arch, while full occlusal coverage is provided for the mandibular dental arch. The axels of the Herbst bite-jumping mechanism are soldered adjacent to the lower first premolars and the upper first molars (Fig.1).

\section{SAMPLE DESCRIPTION}

The research sample consists of a research and control group to test the two hypothesis presented.

I. Experimental Group: Twenty two patients treated with the acrylic splint Herbst were selected from the files of the Department of Orthodontics, School of Dentistry, West Virginia University . 

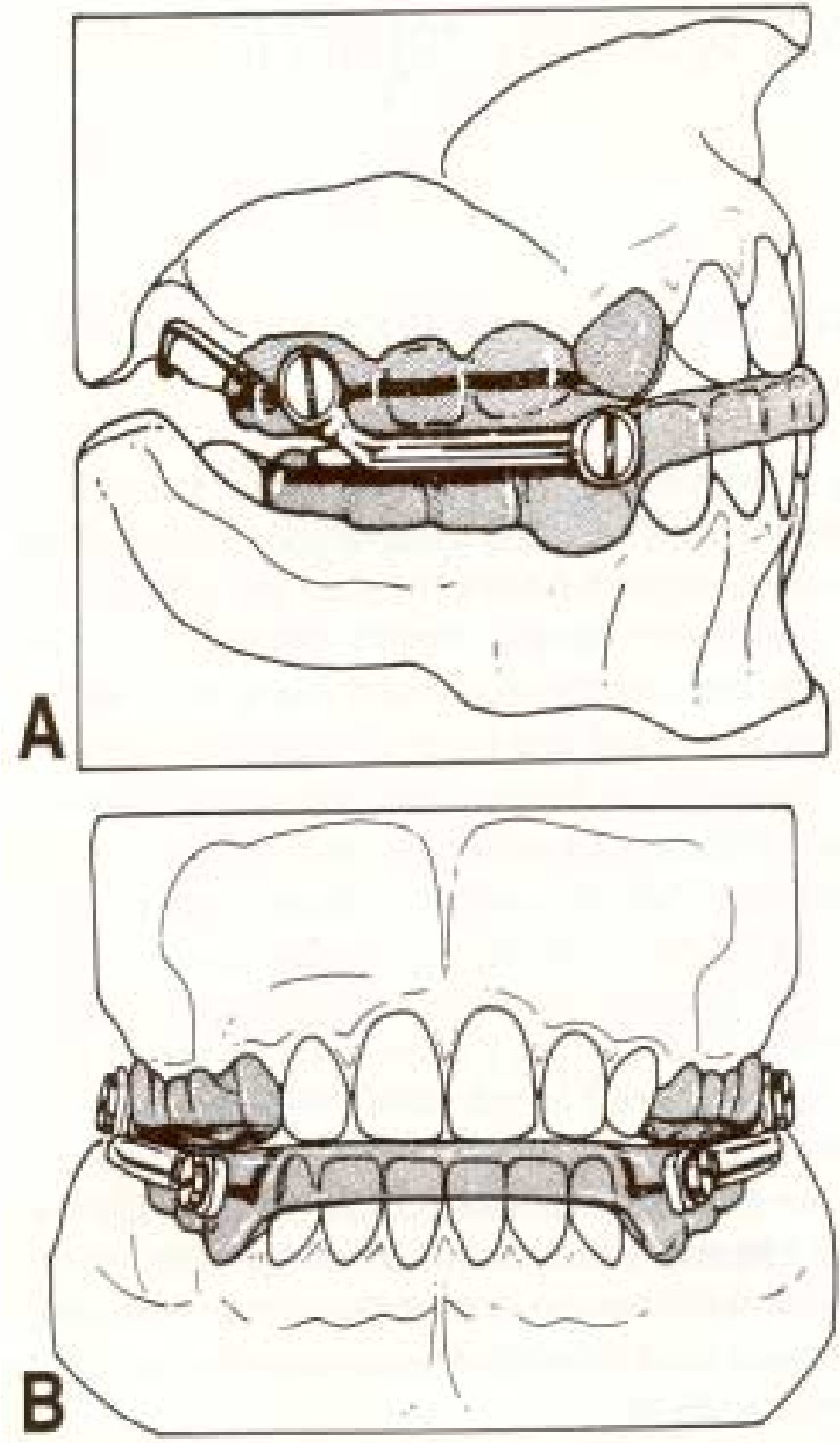

Fig 1. Acrylic splint Herbst appliance: A, lateral aspect; B, frontal aspect. 


\section{The criteria of selection include:}

1. Female and male patients in the mixed and early permanent dentition that were diagnosed with Class II malocclusion with mandibular deficiency.

2. Patients that were treated with acrylic splint Herbst Appliance with bonded upper member and removable lower member.

3. No previous orthodontic treatment

4. Availability of pre-treatment and post-treatment cephalometric radiographs taken within six months after removal of Herbst Appliance.

II. Control Group: Serial cephalometric radiographs of 22 Class II patients with no treatment were selected from the Case Western University Bolton-Brush Study, Cleveland Ohio. These patients were matched in sex, age and craniofacial morphology with the experimental group subjects. (Tables 1 and 2). 
Table 1. Age and sex distribution of treated and control groups.

\begin{tabular}{|l|rrr|rrr|}
\hline & \multicolumn{3}{|c|}{$\begin{array}{c}\text { Treated Group } \\
\text { (years) }\end{array}$} & \multicolumn{3}{c|}{ Control Group } \\
& \multicolumn{3}{|c|}{ (years) } \\
\cline { 2 - 7 }$N$ & All subjects & Female & Male & All Subjects & Female & Male \\
Mean & 11.9 & 10.9 & 13.3 & 11.9 & 10.9 & 13.3 \\
St Dev & 1.9 & 1.7 & 1.2 & 1.9 & 1.7 & 1.3 \\
Max & 14.8 & 13.5 & 14.8 & 15.5 & 13.8 & 15.5 \\
Min & 7.6 & 7.6 & 11.4 & 7.7 & 7.7 & 11.5 \\
\hline
\end{tabular}

Table 2. Starting Dentofacial morphology: treated and control sample.

\begin{tabular}{|c|c|c|c|c|c|c|}
\hline \multirow[t]{2}{*}{ Variables } & \multicolumn{2}{|c|}{ Treated } & \multicolumn{2}{|c|}{ Control } & \multirow[b]{2}{*}{$p$} & \multirow[b]{2}{*}{ Sig. } \\
\hline & Mean & SD & Mean & SD & & \\
\hline Overjet & 7.4 & 2.2 & 6.2 & 2.8 & 0.1364 & NS \\
\hline Molar Relation. & 1.5 & 1.8 & 1.0 & 1.4 & 0.2923 & NS \\
\hline Overbite & 4.0 & 1.8 & 3.7 & 1.6 & 0.6076 & NS \\
\hline $\mathrm{Ml} / \mathrm{Nsl}$ & 34.7 & 6.6 & 35.0 & 6.7 & 0.9105 & NS \\
\hline $\mathrm{Ol} / \mathrm{Nsl}$ & 19.1 & 5.2 & 19.5 & 4.6 & 0.8108 & NS \\
\hline $\mathrm{NI} / \mathrm{Nsl}$ & 6.6 & 4.2 & 6.9 & 3.2 & 0.8435 & NS \\
\hline
\end{tabular}




\title{
METHODOLOGY
}

\author{
IRB approval was obtained from the West Virginia \\ University to use the cephalograms from the WVU Department of \\ Orthodontics and the Bolton Brush Study. (Appendix A)
}

\section{I . CEPHALOMETRIC ANALYSIS}

The registration of the lateral cephalometric images were standardized as to magnification factor and completed on matte cephalometric acetate tracing film (3M Unitek, Monrovia, CA) with a $0.3 \mathrm{~mm}$ mechanical \#2 HB lead pencil by one operator. The landmarks used are defined in Table 3. The reference lines used are defined in Table 4.

TABLE 3. Cephalometric Landmarks.

\begin{tabular}{|c|c|c|}
\hline Symbol & Name & Definition \\
\hline li & incision inferius & $\begin{array}{l}\text { The incisal point of the most } \\
\text { prominent mandibular central incisor }\end{array}$ \\
\hline Is & Incision superius & $\begin{array}{l}\text { The incisal point of the most } \\
\text { prominent maxillar central incisor }\end{array}$ \\
\hline $\mathrm{Mi}$ & molar inferius & $\begin{array}{l}\text { The mesio-buccal cusp tip of the } \\
\text { maxillary first molar }\end{array}$ \\
\hline Ms & molar superius & $\begin{array}{l}\text { The mesio-buccal cusp tip of the } \\
\text { mandibular molar }\end{array}$ \\
\hline $\mathrm{Pg}$ & Pogonion & The most prominent of the chin \\
\hline Ans & $\begin{array}{l}\text { anterior nasal } \\
\text { Spine }\end{array}$ & $\begin{array}{l}\text { The apex of the spina nasalis } \\
\text { anterior }\end{array}$ \\
\hline A pt. & Subspinale & $\begin{array}{l}\text { The deepest point in the concavity } \\
\text { of the anterior maxilla between the } \\
\text { ANS and the alveolar crest }\end{array}$ \\
\hline Pns & $\begin{array}{l}\text { posterior nasal } \\
\text { Spine }\end{array}$ & $\begin{array}{l}\text { The most posterior point on contour } \\
\text { of the plate in the midsagittal plane }\end{array}$ \\
\hline Me & Menton & $\begin{array}{l}\text { The deepest point of the mandibular } \\
\text { symphysis }\end{array}$ \\
\hline go & Gonion & $\begin{array}{l}\text { The lowest point of the bony contour } \\
\text { of the angle of the mandible }\end{array}$ \\
\hline Sella & $S$ & The center of the sella turcica \\
\hline nasion & $N$ & $\begin{array}{l}\text { The most anterior point of the } \\
\text { nasofrontal suture }\end{array}$ \\
\hline
\end{tabular}


Table 4. Cephalometric reference lines

\begin{tabular}{|c|c|c|}
\hline Symbol & Name & Definition \\
\hline NSL & $\begin{array}{l}\text { Nasion-Sella } \\
\text { line }\end{array}$ & $\begin{array}{l}\text { Reference line joining Nasion } \\
\text { and Sella }\end{array}$ \\
\hline $\mathrm{OL}$ & Occlusal Line & $\begin{array}{l}\text { Reference line joining the } \\
\text { maxillary incisal edge and the } \\
\text { Mesio-buccal cusp tip of the } \\
\text { Maxillary first molar }\end{array}$ \\
\hline OLp & $\begin{array}{l}\text { Occlusal Line } \\
\text { Perpendicular }\end{array}$ & $\begin{array}{l}\text { Vertical reference line } \\
\text { perpendicular to the occlusal } \\
\text { Plane and passing through } \\
\text { Sella. }\end{array}$ \\
\hline NL & Maxillary line & $\begin{array}{l}\text { Reference line joining anterior } \\
\text { nasal spine and posterior } \\
\text { Nasal spine }\end{array}$ \\
\hline ML & $\begin{array}{l}\text { Mandibular } \\
\text { line }\end{array}$ & $\begin{array}{l}\text { Reference line joining menton } \\
\text { and gonion }\end{array}$ \\
\hline
\end{tabular}

\section{MEASURING PROCEDURE}

The method of determining the sagittal and vertical movement achieved with the acrylic splint Herbst was modeled after the cephalometric systems described by Pancherz and illustrated in Figure 2 . 


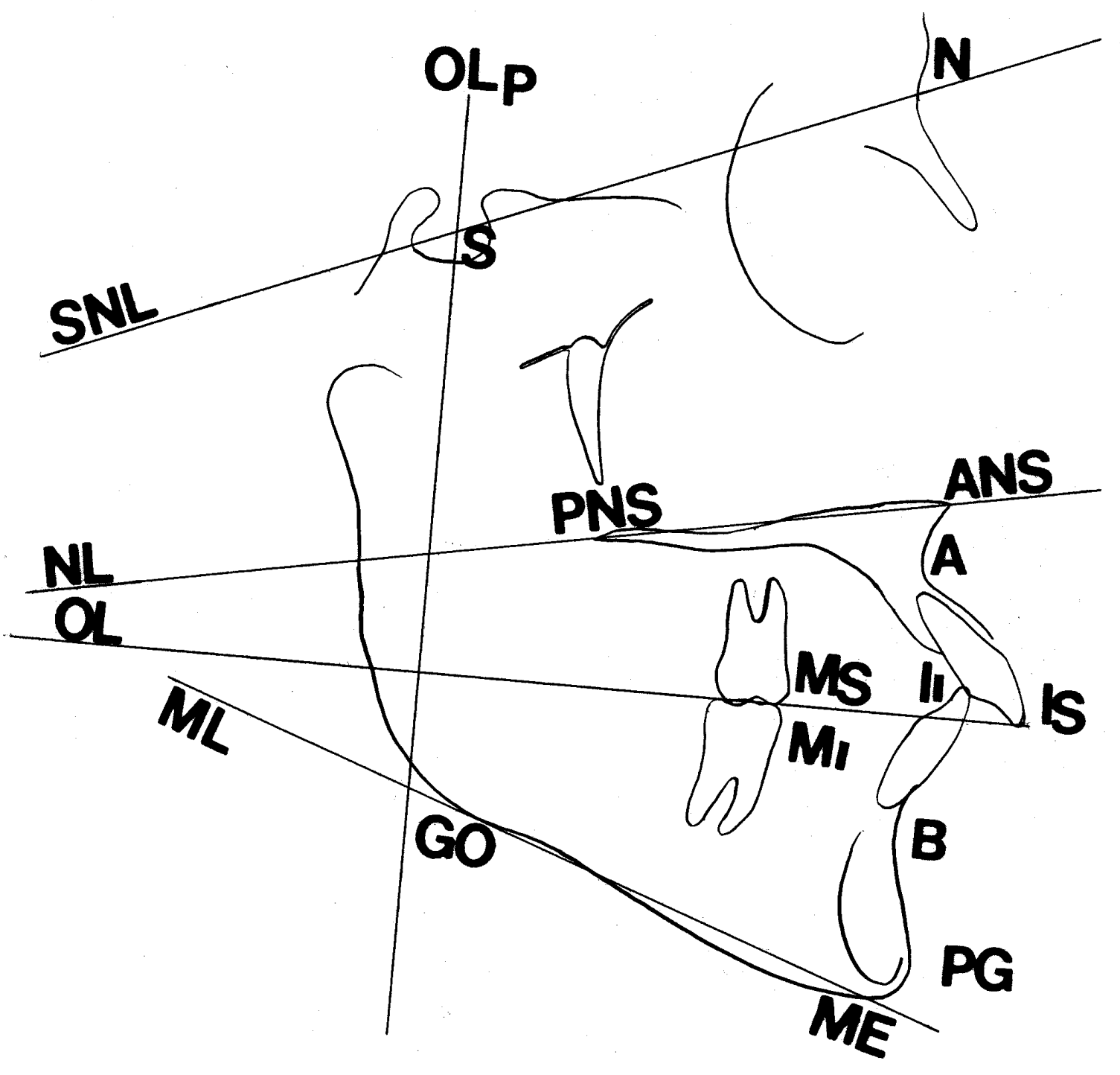

Figure 2. The skeletal and dental cephalometric landmarks and reference lines (see Tables 3 and 4) 
The reference grid utilized in this study was constructed from the occlusal plane (OL) and a vertical line perpendicular to the occlusal plane that passes through point sella. Once constructed, this grid was transferred from the first cephalogram ( $\mathrm{T} 1)$ to the subsequent cephalogram (T2) by superimposing the tracings on the mid-sagittal cranial base structure ${ }^{65}$. All linear measurements were performed parallel to OL and perpendicular to OLp. These measurements are listed in Tables 5 and 6 . In addition to the linear measurements using the reference grid, three angular measurements were used with reference to the cranial base that are listed in Table 6 .

Table 5. Sagittal Measurements.

\begin{tabular}{|l|l|}
\hline Variable (mm) & Definition \\
\hline Is/Olp & Position of maxillary central incisor \\
li/Olp & Position of mandibular central incisor \\
Is/OLp minus li/Olp & Overjet \\
Ms/Olp & Position of the maxillary first molar \\
Mi/Olp & Position of the mandibular first molar \\
Ms/OLp minus Mi/Olp & Molar Relationship \\
A/Olp & Position of the maxillary base \\
Pg/Olp & Position of the mandibular base \\
\hline
\end{tabular}


Table 6. Vertical and Cranial Measurements

\begin{tabular}{|c|c|}
\hline Variable $(\mathrm{mm})\left(^{\circ}\right)$ & Definition \\
\hline Is-NL & $\begin{array}{l}\text { Position of maxillary central } \\
\text { incisor }\end{array}$ \\
\hline & Position of mandibular central \\
\hline li-ML & incisor \\
\hline $\mathrm{i}-\mathrm{OL}$ & Overbite \\
\hline Msc-NL & Position of maxillary first molar \\
\hline Mic-ML & $\begin{array}{l}\text { Position of mandibular first } \\
\text { molar }\end{array}$ \\
\hline$A-O L$ & Position of the maxillary base \\
\hline ANS-Me & Lower facial height \\
\hline ML/NSL $\left(^{\circ}\right)$ & Mandibular plane angle \\
\hline NL/NSL $\left({ }^{\circ}\right)$ & Maxillary plane angle \\
\hline $\mathrm{OL} / \mathrm{NSL}\left({ }^{\circ}\right)$ & Occlusal plane angle \\
\hline
\end{tabular}

STATISTICAL ANALYSIS

Data was analyzed using JMP statistical software on a MacIntosh computer. Intraclass Correlation Coefficient of Reliability was used to determine the reliability of the cephalometric measurements. The Reliability ( $R$ value) is a number between zero and one; where a $R$ value greater than 0.90 indicates high reliability.

The control starting (T1) dentofacial morphology was matched to the experimental group (T1) by using a one-way analysis variance. One-way analysis of variance was also used to compare the treated and control group changes T1-T2. When the $p$-value is less than $0.05(p<0.05)$ the difference between the control and experimental groups is declared significant. 


\section{CHAPTER IV \\ RESULTS AND DISCUSSION}

\section{RESULTS}

This section presents the results and discussion of the effects of the acrylic splint Herbst therapy of 22 individuals treated in the West Virginia University. The results were compared to that of a matched control group according to age, sex, and pretreatment dentofacial morphology as illustrated in Tables 1 and 2 .

Assessments of individual changes were made, and the arithmetic mean, standard deviations, minimum, and maximum values (millimeters and degrees) were calculated separately for the treated and control group (Tables 9,10,11 and 12).

The effects with the acrylic splint Herbst in the treated group were compared with the control group, and their differences were tested for statistical significance. The results are discussed in the following order:

I. Reliability of cephalometric measurements

II. Comparison of treated group vs. control group

III. Individual sagittal changes

IV. Individual vertical changes

V. Skeletal and dental contributions to the changes in overjet and molar relationship. 
I. Reliability of Cephalomettric Measurements. This section describes errors in location of landmarks, measurements, and superimposition performed by one examiner (intra-examiner error). The Intraclass Correlation Coefficient of Reliability (I.C.C.R.) for all sagittal, vertical and angular measurements were found to be greater than 0.9800, indicating that the measurements made are quite reliable (Table 7).

Table 7. Intraclass Correlation Coefficient of Reliability

\begin{tabular}{|c|r|r|r|r|}
\hline Variable & Group & MSA & MSE & Reliability \\
\hline OLp-A & Treated & 21.6729 & 0.0714 & 0.9967 \\
\hline OLp-Pg & Treated & 15.6190 & 0.0000 & 1.0000 \\
\hline Is/OLp & Treated & 19.6190 & 4.0714 & 0.9810 \\
\hline li/OLp & Treated & 11.6100 & 0.0000 & 1.0000 \\
\hline Overjet & Treated & 17.6190 & 0.0000 & 1.0000 \\
\hline Ms/OLp & Treated & 3.3300 & 0.0000 & 1.0000 \\
\hline Mi/OLp & Treated & 10.2857 & 0.0000 & 1.0000 \\
\hline Molar Relation & Treated & 11.6190 & 0.0000 & 1.0000 \\
\hline A-OL & Treated & 30.2857 & 0.0000 & 1.0000 \\
\hline li/OL & Treated & 5.6428 & 0.0714 & 0.9875 \\
\hline ANS-Me & Treated & 84.4524 & 0.3571 & 0.9957 \\
\hline Is/NL & Treated & 20.5000 & 0.1429 & 0.9930 \\
\hline $\mathrm{li} / \mathrm{ML}$ & Treated & 16.2857 & 0.0000 & 1.0000 \\
\hline $\mathrm{Msc/NL}$ & Treated & 21.1667 & 0.0000 & 1.0000 \\
\hline $\mathrm{Mic/ML}$ & Treated & 22.1667 & 0.1429 & 0.9932 \\
\hline $\mathrm{ML} / \mathrm{NSL}$ & Treated & 60.7381 & 0.0714 & 0.9998 \\
\hline $\mathrm{OL} / \mathrm{NSL}$ & Treated & 22.2857 & 0.2857 & 0.9873 \\
\hline $\mathrm{NL} / \mathrm{NSL}$ & Treated & 40.6667 & 0.0000 & 1.0000 \\
\hline
\end{tabular}


II. Comparison of Treated vs. Control group.

Treatment effects with the acrylic splint Herbst in the treated group were compared with the control group (Table 8 and 9). A two-tailed t-test (ANOVA) was used to determine statistical differences between the two groups. Statistical significant differences were found in 10 of the 18 variables measured.

For sagittal changes (Table 8), no significant differences were found in the upper incisor position (Is/OLp) and the mandibular base position (Pg/OLp). Significant differences were found in the changes in overjet (Is/OLpIi/OLp), lower incisors (Ii/Olp), lower molars (Ms/Olp), molar relation (Ms/OLp-Mi/OLp, p<0.001), upper molars (Ms/OLp) $(\mathrm{p}<0.01)$, and maxillary base (A/OLp, $\mathrm{p}<0.05)$.

Table 8. Sagittal measurements comparison of Treated vs. Control Group

\begin{tabular}{|c|c|c|c|c|c|}
\hline & \multicolumn{2}{|c|}{ Treated (T1-T2) } & \multicolumn{2}{|c|}{ Control (T1-T2) } & \multirow[t]{2}{*}{ Sig } \\
\hline Variable & Mean & $S D$ & Mean & SD & \\
\hline \multicolumn{6}{|c|}{ Sagittal (mm): } \\
\hline Is/Olp & -0.4 & 2.4 & -1.9 & 2.7 & NS \\
\hline li/Olp & -4.9 & 2.5 & -1.8 & 2.6 & $* * *$ \\
\hline Overjet & 4.4 & 2.4 & -0.2 & 1.1 & *** \\
\hline $\mathrm{Ms} / \mathrm{Olp}$ & 0.5 & 3.5 & -2 & 2.8 & ** \\
\hline Mi/Olp & -5 & 2.7 & -1.9 & 3.1 & $* * *$ \\
\hline Molar Rel & 5.7 & 2.9 & -0.1 & 1.8 & 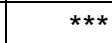 \\
\hline A/Olp & -0.4 & 2.3 & -1.9 & 2.1 & * \\
\hline $\mathrm{Pg} / \mathrm{Olp}$ & -3.8 & 3.3 & -2.6 & 3.3 & NS \\
\hline
\end{tabular}


For vertical changes (Table 9), no significant differences were found in the changes in maxillary base position, lower facial height, upper incisor position, upper molar, lower molar and mandibular plane angle. Significant differences were found in overbite changes and lower incisor changes $(p<0.001)$, nasal plane angle $(\mathrm{p}<0.01)$ and occlusal plane angle $(\mathrm{p}<0.05)$.

Table 9. Vertical measurements comparison of treated vs. control group.

\begin{tabular}{|c|c|c|c|c|c|}
\hline Vertical (mm): & Treate & $(T 1-T 2)$ & Control(T1 & $-\mathrm{T} 2)$ & Sig \\
\hline & Mean & SD & Mean & SD & \\
\hline A-OI & -0.5 & 2.2 & $\begin{array}{l}-0.1 \\
\end{array}$ & 1.3 & NS \\
\hline Overbite & 2.5 & 2.1 & -0.2 & 0.8 & $* * *$ \\
\hline Ans-Me & -1.6 & 3.2 & -0.8 & 1.3 & NS \\
\hline $\mid \mathrm{IS}-\mathrm{NI}$ & -0.7 & 2.1 & 0.1 & 1.3 & NS \\
\hline li-Ml & 0.2 & 0.9 & -0.8 & 1.1 & $* * *$ \\
\hline Msc-NI & -0.1 & 2 & -0.1 & 1.1 & NS \\
\hline Mic-Ml & -1.1 & 1.6 & -0.5 & 1.9 & NS \\
\hline \multicolumn{6}{|l|}{ Angular (o): } \\
\hline Ml/Nsl & 0.6 & 2.5 & 0 & 2.3 & NS \\
\hline $\mathrm{Ol} / \mathrm{Nsl}$ & -1.8 & 5 & 0.7 & 1.7 & * \\
\hline $\mathrm{NI} / \mathrm{Nsl}$ & -1.4 & 2.6 & 0.4 & 1.6 & ** \\
\hline
\end{tabular}

NS $=$ not significant

* $\quad$ Significant at $\mathrm{p}<0.05$

$\star \star \quad=$ Significant at $\mathrm{p}<0.01$

$\star \star \star=$ Significant at $\mathrm{p}<0.001$

\section{Individual Sagittal Changes.}

The individual sagittal cephalometrics changes of the control and treated groups are summarized in Tables 10 and 11 , respectively 
Control group changes (Table 10). In most of the subjects, the overjet did not change or got worse. Only in four subjects did the overjet improved (cases \#, 3, 7,13 and 17). These improvements were of $1 \mathrm{~mm}$ with the exception of subject \# 17, which improved by $3 \mathrm{~mm}$. The mean change was an increase of $0.2 \mathrm{~mm}$, with a varaiation ranging from -3 to $3 \mathrm{~mm}$.

In the upper incisors there was a mean mesial movement of $1.9 \mathrm{~mm}$, with a wide variation ranging from -10 to $5 \mathrm{~mm}$. There was no consistent pattern found in these changes. In the lower incisors there was mean mesial movement of $1.8 \mathrm{~mm}$, with a variation ranging from -9 to $2 \mathrm{~mm}$.

The upper molar showed a mean mesial movement of $2.0 \mathrm{~mm}$, with a variation ranging from -9 to $4 \mathrm{~mm}$. The lower molar showed similar changes with a mean mesial movement of $1.9 \mathrm{~mm}$ and a variation that ranges from -9 to $3 \mathrm{~mm}$. The molar relationship increase towards a Class II molar relation by 0.1 $\mathrm{mm}$ in average, with a variation ranging from -5 to $4 \mathrm{~mm}$.

The maxillary base was increased in length in all the subjects except, in 3 subjects (\# 1, 3 and 19). Cases 1 and 19 showed a decrease in length of $1 \mathrm{~mm}$ and \# 3 decreased by $3 \mathrm{~mm}$. The mean increase was $1.9 \mathrm{~mm}$ in average, with a variation ranging from -6 to $3 \mathrm{~mm}$. 
The mandibular base increase in length in all subjects except in 2 subjects (\# 3 and 19), they decreased by 3 and 1 $\mathrm{mm}$ respectively. The mean increase was $2.6 \mathrm{~mm}$ with a wide variation ranging from -13 to $4 \mathrm{~mm}$.

Table 10. Individual sagittal changes $(\mathrm{mm})$ of subjects in the control group between $\mathrm{T} 1-\mathrm{T} 2$

\begin{tabular}{|c|c|c|c|c|c|c|c|c|}
\hline Subjects & Overjet & $\begin{array}{l}\text { Maxillary } \\
\text { Incisor }\end{array}$ & $\begin{array}{l}\text { Mandibular } \\
\text { incisor }\end{array}$ & $\begin{array}{l}\text { Maxillary } \\
\text { Molar }\end{array}$ & $\begin{array}{l}\text { Mandibular } \\
\text { Molar }\end{array}$ & $\begin{array}{l}\text { Molar } \\
\text { Relationship }\end{array}$ & $\begin{array}{l}\text { Maxillary } \\
\text { Base }\end{array}$ & $\begin{array}{l}\text { Mandibular } \\
\text { Base }\end{array}$ \\
\hline 1 & -1 & 0 & 1 & -1 & 0 & -1 & 1 & 0 \\
\hline 2 & 0 & -3 & -3 & -3 & . & & -3 & -5 \\
\hline 3 & 1 & 5 & 2 & 4 & 3 & 1 & 3 & 4 \\
\hline 4 & 0 & -2 & -2 & -2 & -2 & 0 & -3 & -1 \\
\hline 5 & -1 & -10 & -9 & -9 & -9 & 0 & -6 & -13 \\
\hline 6 & 0 & -2 & -2 & -5 & -9 & 4 & -1 & -4 \\
\hline 7 & 1 & -2 & -3 & -4 & -5 & 1 & -2 & -5 \\
\hline 8 & -3 & -3 & 0 & 1 & 0 & 1 & -2 & -3 \\
\hline 9 & 0 & -4 & -4 & -2 & -1 & -1 & -1 & -3 \\
\hline 10 & -1 & 0 & 1 & -1 & -3 & 2 & -2 & 0 \\
\hline 11 & 0 & 0 & 0 & 1 & 1 & 0 & -1 & 0 \\
\hline 12 & -1 & -3 & -2 & -4 & -2 & -2 & -2 & -2 \\
\hline 13 & 1 & -3 & -4 & -4 & -3 & -1 & -3 & -4 \\
\hline 14 & -2 & 0 & 2 & -2 & -2 & 0 & 0 & -1 \\
\hline 15 & 0 & -4 & -4 & 2 & 0 & 2 & -3 & -5 \\
\hline 16 & 0 & 0 & 0 & -2 & -1 & -1 & -6 & 0 \\
\hline 17 & 3 & -2 & -5 & -2 & -1 & -1 & -2 & -2 \\
\hline 18 & 0 & 0 & 0 & -4 & -2 & -2 & -3 & -3 \\
\hline 19 & 0 & 1 & 1 & 2 & 1 & 1 & 1 & 1 \\
\hline 20 & 0 & -2 & -2 & -3 & -2 & -1 & -1 & -3 \\
\hline 21 & -1 & -3 & -2 & -2 & 3 & -5 & -3 & -4 \\
\hline 22 & 0 & -4 & -4 & -4 & -5 & 1 & -4 & -5 \\
\hline Mean & -0.2 & -1.9 & -1.8 & -2.0 & -1.9 & -0.1 & -1.9 & -2.6 \\
\hline SD & 1.1 & 2.7 & 2.6 & 2.8 & 3.1 & 1.8 & 2.1 & 3.3 \\
\hline Min & -3 & -10 & -9 & -9 & -9 & -5 & -6 & -13 \\
\hline Max & 3 & 5 & 2 & 4 & 3 & 4 & 3 & 4 \\
\hline
\end{tabular}


Treated group changes (Table 11). A decrease in overjet correction was found in all subjects treated with the Herbst appliance, except subject no.4, in which there was a $1 \mathrm{~mm}$ increase in overjet. The average change in overjet correction was $4.4 \mathrm{~mm}$ and the variation in overjet changes were wide, ranging from -1 to $8 \mathrm{~mm}$.

In general, the effect of the acrylic splint Herbst on the maxillary base was small with a mean increase in length of $0.4 \mathrm{~mm}$. However the variation was wide, ranging from $-4 \mathrm{~mm}$ to $7 \mathrm{~mm}$.

There was a mandibular base length increase in all subjects except subjects \#'s 4 and 10, in which the mandibular length decrease by 1 and $3 \mathrm{~mm}$, respectively. The mean increase in mandibular base length was $3.8 \mathrm{~mm}$, with a variation ranging from -10 to $3 \mathrm{~mm}$.

The effect on the upper incisors was small with a mean mesial movement of $0.4 \mathrm{~mm}$, but the variation was wide ranging from -4 to $6 \mathrm{~mm}$. The lower incisors were found to move mesially with treatment in all subjects. The mean sagittal distance was large $(-4.9 \mathrm{~mm})$ with a wide variation ranging from -1 to $-10 \mathrm{~mm}$.

Mesial movement of lower molars was found in all subjects except on subject \# 16, in which there was no change. The average mesial movement was $5 \mathrm{~mm}$ with a range from -11 to 
$0 \mathrm{~mm}$. Distal movement of upper molars was found to be $0.5 \mathrm{~mm}$ on average with a wide variation ranging from -7 to $8 \mathrm{~mm}$. The molar relationship moved towards a Class I or Class III relationship in all the subjects. The mean movement was of 5.7 $\mathrm{mm}$, with a variation ranging from 2 to $12 \mathrm{~mm}$.

Table 11. Individual sagittal changes $(\mathrm{mm})$ of subjects in the treated group between $\mathrm{T}_{1}-\mathrm{T} 2$

\begin{tabular}{|c|c|c|c|c|c|c|c|c|}
\hline Subjects & Overjet & $\begin{array}{l}\text { Maxillary } \\
\text { incisor }\end{array}$ & $\begin{array}{l}\text { Mandibular } \\
\text { incisor }\end{array}$ & $\begin{array}{l}\text { Maxillary } \\
\text { Molar }\end{array}$ & $\begin{array}{l}\text { Mandibular } \\
\text { Molar }\end{array}$ & $\begin{array}{l}\text { Molar } \\
\text { Relationship }\end{array}$ & $\begin{array}{l}\text { Maxillary } \\
\text { Base }\end{array}$ & $\begin{array}{l}\text { Mandibular } \\
\text { Base }\end{array}$ \\
\hline 1 & 8 & -2 & -10 & 2 & -10 & 12 & 0 & -9 \\
\hline 2 & 1 & -4 & -5 & 0 & -6 & 6 & -1 & -4 \\
\hline 3 & 5 & -1 & -6 & -2 & -7 & 5 & -1 & -6 \\
\hline 4 & -1 & -2 & -1 & 1 & -2 & 3 & 0 & 1 \\
\hline 5 & 2 & 1 & -5 & 2 & -6 & 8 & 1 & -3 \\
\hline 6 & 6 & 2 & -4 & 6 & -3 & 9 & 0 & -2 \\
\hline 7 & 4 & -2 & -6 & 4 & -7 & 11 & 7 & \\
\hline 8 & 3 & 0 & -3 & -4 & -6 & 2 & -1 & -8 \\
\hline 9 & 6 & -1 & -7 & -1 & -5 & 4 & -4 & -3 \\
\hline 10 & 6 & 4 & -2 & 2 & -3 & 5 & -1 & 3 \\
\hline 11 & 6 & -2 & -8 & -7 & -11 & 4 & -3 & -10 \\
\hline 12 & 6 & -3 & -9 & -7 & -9 & 2 & -2 & -9 \\
\hline 13 & 1 & 0 & -1 & 3 & -1 & 4 & -3 & -1 \\
\hline 14 & 5 & -1 & -6 & 0 & -5 & 5 & -1 & -5 \\
\hline 15 & 7 & -2 & -9 & 1 & -7 & 8 & -3 & -5 \\
\hline 16 & 0 & -3 & -3 & -3 & 0 & 3 & 0 & -2 \\
\hline 17 & 5 & 1 & -4 & 1 & -5 & 8 & 2 & -2 \\
\hline 18 & 8 & 6 & -2 & 8 & -3 & 11 & 3 & -2 \\
\hline 19 & 6 & 3 & -3 & 2 & -3 & 5 & 0 & -2 \\
\hline 20 & 3 & -2 & -5 & 0 & -3 & 3 & -1 & -2 \\
\hline 21 & 5 & 0 & -5 & 1 & -4 & 5 & 0 & -3 \\
\hline 22 & 4 & 0 & -4 & 1 & -4 & 5 & 0 & -5 \\
\hline Mean & 4.4 & -0.4 & -4.9 & 0.5 & -5 & 5.7 & -0.4 & -3.8 \\
\hline SD & 2.4 & 2.4 & 2.5 & 3.5 & 2.7 & 2.9 & 2.3 & 3.3 \\
\hline Min & -1 & -4 & -10 & -7 & -11 & 2 & -4 & -10 \\
\hline Max & 8 & 6 & -1 & 8 & 0 & 12 & 7 & 3 \\
\hline
\end{tabular}




\section{Individual Vertical Changes.}

The vertical cephalometric changes of the control and treated groups are shown in Tables 12 and 13 .

Control group changes (Table 12). The maxillary base did not change significantly $(-0.1 \mathrm{~mm})$, but varied within a range of -3 to $3 \mathrm{~mm}$. The lower facial height increased for all except two subjects (\#'s 19 and 22), in which the lower facial height decrease was 2 and $1 \mathrm{~mm}$, respectively. The mean increase reported was $0.8 \mathrm{~mm}$, with a variation ranging from -4 to $2 \mathrm{~mm}$.

The overbite was increased for all except 3 subjects (\#'s 4,11 and 21), and the increment was $1 \mathrm{~mm}$ for subjects \#'s 4 and 21, and $2 \mathrm{~mm}$ for subject \# 11. The mean overbite increased by $0.2 \mathrm{~mm}$, with a variation ranging from -2 to $2 \mathrm{~mm}$. Maxillary incisors exhibited no consistent pattern and there was not any significant change $(0.1 \mathrm{~mm})$. The variation ranged from -2 to 2 $\mathrm{mm}$. Mandibular incisors extruded $0.8 \mathrm{~mm}$ in average, with a variation ranging from -4 to $1 \mathrm{~mm}$.

Maxillary molars did not show any significant extrusion on average $(0.1 \mathrm{~mm})$, but a variation ranging from -3 to $2 \mathrm{~mm}$ was observed. Mandibular molars extruded by $0.5 \mathrm{~mm}$, with a variation ranging from -7 to $3 \mathrm{~mm}$. 
Mandibular plane angle did not show any change on average $(0.0 \mathrm{~mm})$, but did show a variation ranging from -5 to 4 degrees. The occlusal plane and palatal plane did not change significantly $(0.7$ and 0.4 degrees, respectively) but did show variations ranging from -3 to 5 degrees and -4 to 6 degrees (respectively) for each.

Table 12. Individual vertical changes $(\mathrm{mm})$ or (degrees) of subjects in the control group between $\mathrm{T} 1-\mathrm{T} 2$

\begin{tabular}{ccccccccccc}
\hline Subjects & $\begin{array}{c}\text { Maxillary } \\
\text { base }\end{array}$ & $\begin{array}{c}\text { Overbite } \\
\text { LFH }\end{array}$ & $\begin{array}{c}\text { Maxillary } \\
\text { Incisor }\end{array}$ & $\begin{array}{l}\text { Mandibular } \\
\text { Incisor }\end{array}$ & $\begin{array}{c}\text { Maxillary } \\
\text { Molar }\end{array}$ & $\begin{array}{c}\text { Mandibular } \\
\text { molar }\end{array}$ & MI/NsI & Ol/NsI & NI/Nsl \\
\hline 1 & 0 & 0 & -1 & 0 & -1 & -1 & 1 & 0 & 0 & 0 \\
2 & 0 & 0 & 0 & 2 & 1 & 0 & & 3 & 5 & 1 \\
3 & 0 & 0 & 0 & 1 & -1 & 0 & -1 & -4 & -1 & -4 \\
4 & 0 & 1 & -2 & -1 & -1 & -1 & -1 & -2 & 0 & 0 \\
5 & -1 & 0 & -1 & 1 & -1 & 2 & 0 & 4 & 1 & 0 \\
6 & 2 & 0 & 0 & 1 & 0 & -1 & -1 & 4 & 1 & 0 \\
7 & 1 & -1 & -2 & 0 & 0 & -1 & -1 & 0 & 0 & 0 \\
8 & 0 & 0 & 0 & 0 & -1 & 1 & -1 & 2 & 1 & 1 \\
9 & 0 & 0 & -1 & -1 & -2 & -1 & -1 & -1 & 2 & 1 \\
10 & -2 & -1 & -2 & 4 & 0 & -2 & -1 & -2 & -1 & 0 \\
11 & 0 & 2 & -1 & -2 & 1 & -1 & 0 & 0 & 1 & 1 \\
12 & 0 & -1 & 0 & 0 & -1 & -2 & 1 & 1 & 3 & 1 \\
13 & -3 & -1 & 0 & 1 & -1 & -1 & -1 & 1 & 0 & 0 \\
14 & -2 & -2 & 0 & -2 & -1 & -3 & 0 & 0 & 1 & 0 \\
15 & 0 & 0 & -1 & 0 & -1 & 0 & 0 & 2 & 1 & 0 \\
16 & 0 & -1 & -4 & -1 & -4 & -2 & -3 & -5 & -3 & 6 \\
17 & 0 & -1 & -3 & 0 & -2 & -1 & -2 & -2 & 0 & 1 \\
18 & -2 & 0 & -1 & -1 & -1 & -1 & -7 & -2 & -1 & 0 \\
19 & 0 & 0 & 2 & 0 & 0 & 0 & 3 & 0 & 0 & 0 \\
20 & 2 & 0 & 0 & 0 & 0 & -2 & 1 & 0 & 0 & 0 \\
21 & -1 & 1 & -3 & -1 & -2 & -2 & 1 & 0 & 3 & 1 \\
22 & 3 & -1 & 1 & 1 & 0 & -1 & 1 & 2 & 4 & 0 \\
Mean & -0.1 & -0.2 & -0.8 & 0.1 & -0.8 & -0.1 & -0.5 & 0.0 & 0.7 & 0.4 \\
SD & 1.3 & 0.8 & 1.3 & 1.3 & 1.1 & 1.1 & 1.9 & 2.3 & 1.7 & 1.6 \\
Min & -3 & -2 & -4 & -2 & -4 & -3 & -7 & -5 & -3 & -4 \\
Max & 3 & 2 & 2 & 4 & 1 & 2 & 3 & 4 & 5 & 6 \\
\hline
\end{tabular}


Treatment changes(Table 13). The maxillary base change was small, with a mean downward movement value of $0.5 \mathrm{~mm}$. and a range of -5 to $6 \mathrm{~mm}$. The overbite reduction was found in all cases except on two subjects (\#'s 13 and 18), in which there was a $1 \mathrm{~mm}$ increase in overbite. The mean value for the overbite correction was $2.5 \mathrm{~mm}$, but the variation was wide, ranging from -1 to $7 \mathrm{~mm}$.

The lower facial height was found to increase in most of the subjects. In three subjects (\#'s 1, 11 and 13), the lower facial height was reduced. Lower molar eruption was enhanced by $1.1 \mathrm{~mm}$ with a variation ranging from -5 to $2 \mathrm{~mm}$. Slight intrusion was found with upper molars $(0.1 \mathrm{~mm})$ with a variation ranging from -6 to $3 \mathrm{~mm}$. Lower incisor intrusion of $0.2 \mathrm{~mm}$ was found with a variation ranging from -1 to $2 \mathrm{~mm}$. Upper incisor extrusion of $0.7 \mathrm{~mm}$ was found with a variation ranging from -7 to $4 \mathrm{~mm}$.

The changes in mandibular plane angle were minimal $(-0.6 \mathrm{~mm})$ with a variation ranging from -9 to $5 \mathrm{~mm}$. The change in occlusal plane was in a counter-clockwise direction by 1.8 degrees with a wide range ranging from -13 to 10 degrees. The nasal plane angle was rotated in the same direction by 1.4 degrees with a variation ranging from -9 to 3 degrees. 
Table 13. Individual vertical changes $(\mathrm{mm})$ or (degrees) of subjects in the treated group between T1-T2

\begin{tabular}{|c|c|c|c|c|c|c|c|c|c|c|}
\hline Subject & $\begin{array}{l}\text { Maxillary } \\
\text { base }\end{array}$ & Overbite & LFH & $\begin{array}{l}\text { Maxillary } \\
\text { incisor }\end{array}$ & $\begin{array}{l}\text { Mandibular } \\
\text { incisor }\end{array}$ & $\begin{array}{l}\text { Maxillary } \\
\text { Molar }\end{array}$ & $\begin{array}{l}\text { Mandibular } \\
\text { Molar }\end{array}$ & $\mathrm{Ml} / \mathrm{Nsl}$ & $\mathrm{Ol} / \mathrm{Nsl}$ & $\mathrm{Nl} / \mathrm{Nsl}$ \\
\hline 1 & -3 & 0 & 6 & 4 & 0 & 3 & 1 & 1 & -3 & -6 \\
\hline 2 & 2 & 6 & -4 & 0 & 0 & -1 & 1 & -2 & 3 & 0 \\
\hline 3 & 6 & 3 & -1 & 0 & 0 & 2 & 0 & 0 & -2 & 0 \\
\hline 4 & -1 & 3 & -3 & 0 & 0 & 0 & -3 & -2 & -2 & -4 \\
\hline 5 & 1 & 2 & -2 & -2 & 1 & -1 & -1 & -2 & 1 & -2 \\
\hline 6 & -4 & 3 & -2 & -1 & 0 & 1 & -3 & 1 & -8 & -5 \\
\hline 7 & 2 & 6 & -2 & 0 & 0 & 0 & -2 & -2 & -3 & -4 \\
\hline 8 & -1 & 0 & -1 & -1 & 0 & -1 & -2 & 1 & -3 & 0 \\
\hline 9 & -5 & 2 & -3 & -1 & 1 & 0 & -1 & -1 & -5 & -1 \\
\hline 10 & 0 & 3 & -5 & -1 & -1 & 0 & -2 & -9 & -13 & -9 \\
\hline 11 & -1 & 3 & 5 & -1 & 0 & -3 & -5 & -1 & 7 & 0 \\
\hline 12 & -1 & 2 & -3 & 0 & -1 & -6 & 0 & -1 & 7 & 0 \\
\hline 13 & 0 & -1 & 3 & 0 & -1 & 2 & 0 & 0 & -4 & -2 \\
\hline 14 & -3 & 5 & -5 & -3 & 1 & 1 & -1 & -2 & -4 & 3 \\
\hline 15 & 1 & 7 & -1 & 2 & 2 & 2 & -4 & 5 & 10 & 0 \\
\hline 16 & -1 & 3 & -1 & 0 & 2 & -2 & -1 & 2 & -3 & 0 \\
\hline 17 & -2 & 1 & -2 & -7 & 0 & 0 & 0 & -2 & -5 & -2 \\
\hline 18 & -1 & -1 & -2 & -2 & -1 & 2 & -1 & 1 & -5 & 0 \\
\hline 19 & 0 & 2 & 0 & 0 & 2 & 0 & -1 & 0 & -2 & 0 \\
\hline 20 & 0 & 1 & -5 & -4 & -1 & -3 & 0 & -1 & -3 & 0 \\
\hline 21 & 0 & 4 & -8 & 0 & 1 & 2 & -2 & -1 & -3 & 0 \\
\hline 22 & 0 & 2 & 0 & 1 & 0 & 0 & 2 & 1 & 0 & 0 \\
\hline Mean & -0.5 & 2.5 & -1.6 & -0.7 & 0.2 & -0.1 & -1.1 & -0.6 & -1.8 & -1.4 \\
\hline SD & 2.2 & 2.1 & 3.2 & 2.1 & 0.9 & 2.0 & 1.6 & 2.5 & 5.0 & 2.6 \\
\hline Min & -5 & -1 & -8 & -7 & -1 & -6 & -5 & -9 & -13 & -9 \\
\hline Max & 6 & 7 & 6 & 4 & 2 & 3 & 2 & 5 & 10 & 3 \\
\hline
\end{tabular}




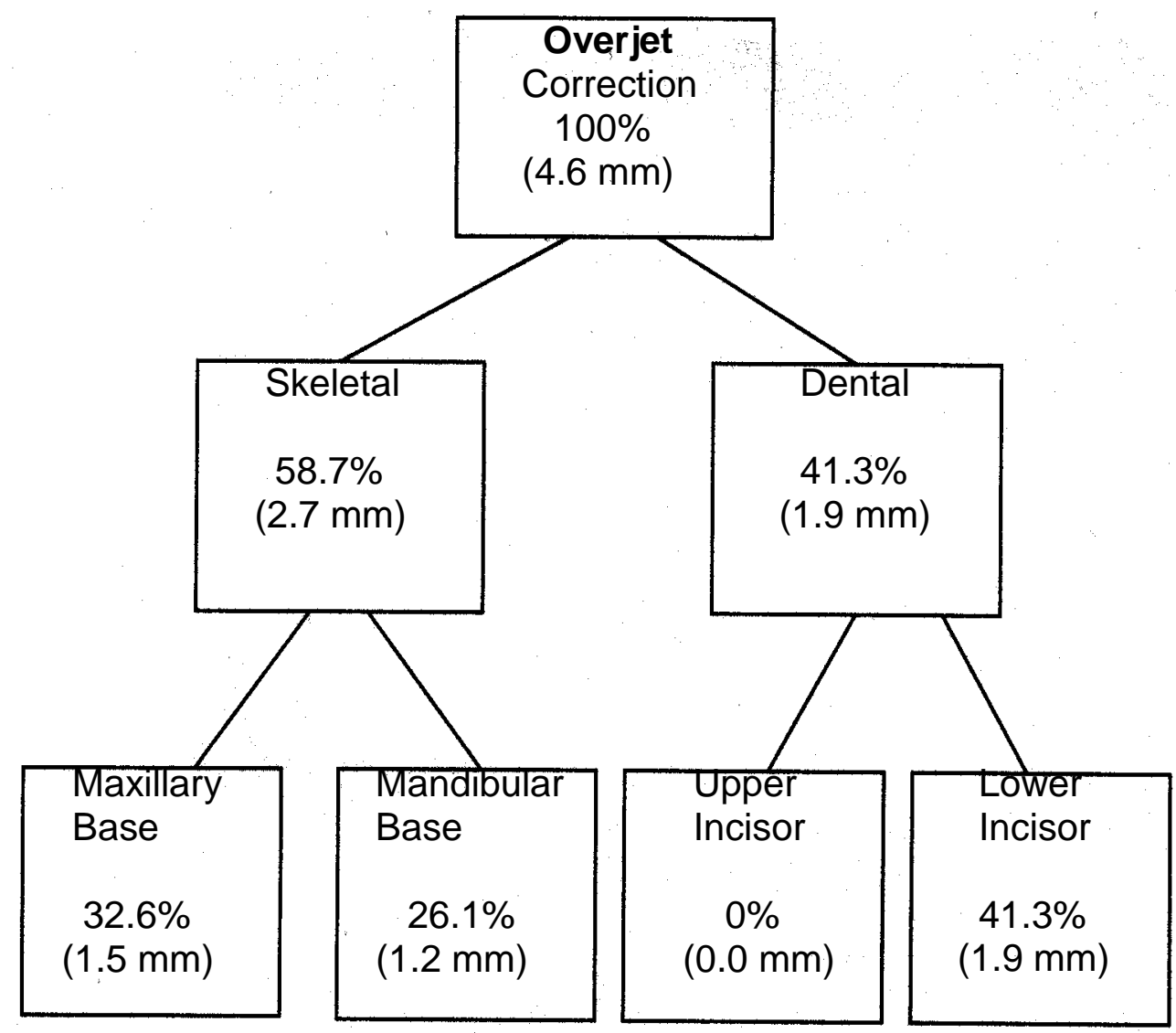

Figure 3. Skeletal and dental contributions to the overjet correction.

v. Comparison of the skeletal and dental contributions to the correction of overjet and molar relationship.

After treatment, all subjects were corrected to a Class I or Class III dental relationship. The skeletal and dental contributions to the correction in overjet and molar 
relationship are illustrated in Tables 3 and 4 . The average overjet improvement in the treated group was of $4.4 \mathrm{~mm}$; when growth is subtracted the total overjet correction was $4.6 \mathrm{~mm}$. The contribution for the maxillary base, mandibular base, upper incisor and mandibular incisor was calculated in the same way. The calculations resulting in this contribution are listed in Table 14.

Table 14. Overjet calculations

\section{Overjet Correction}

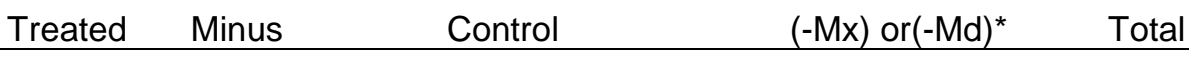

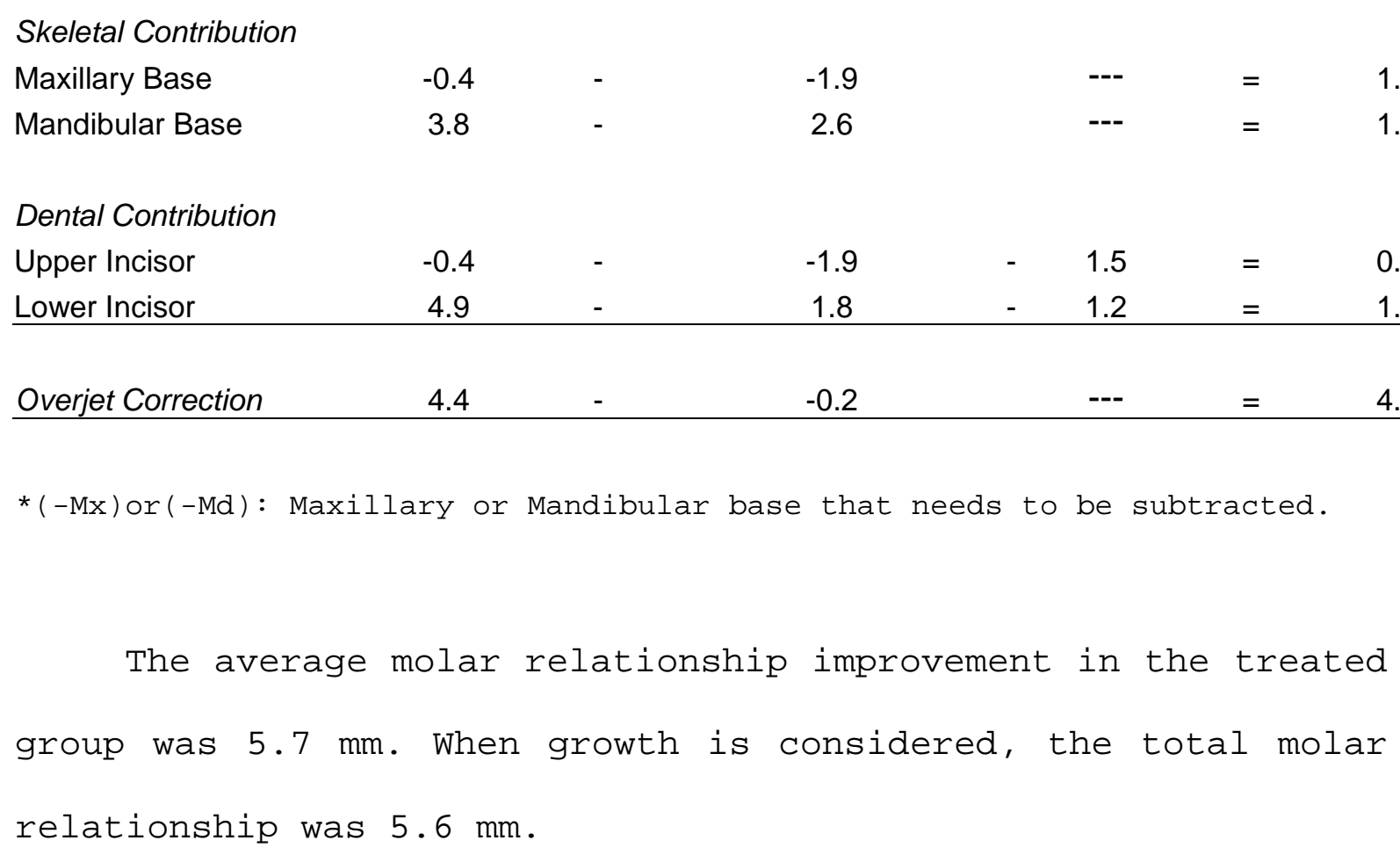




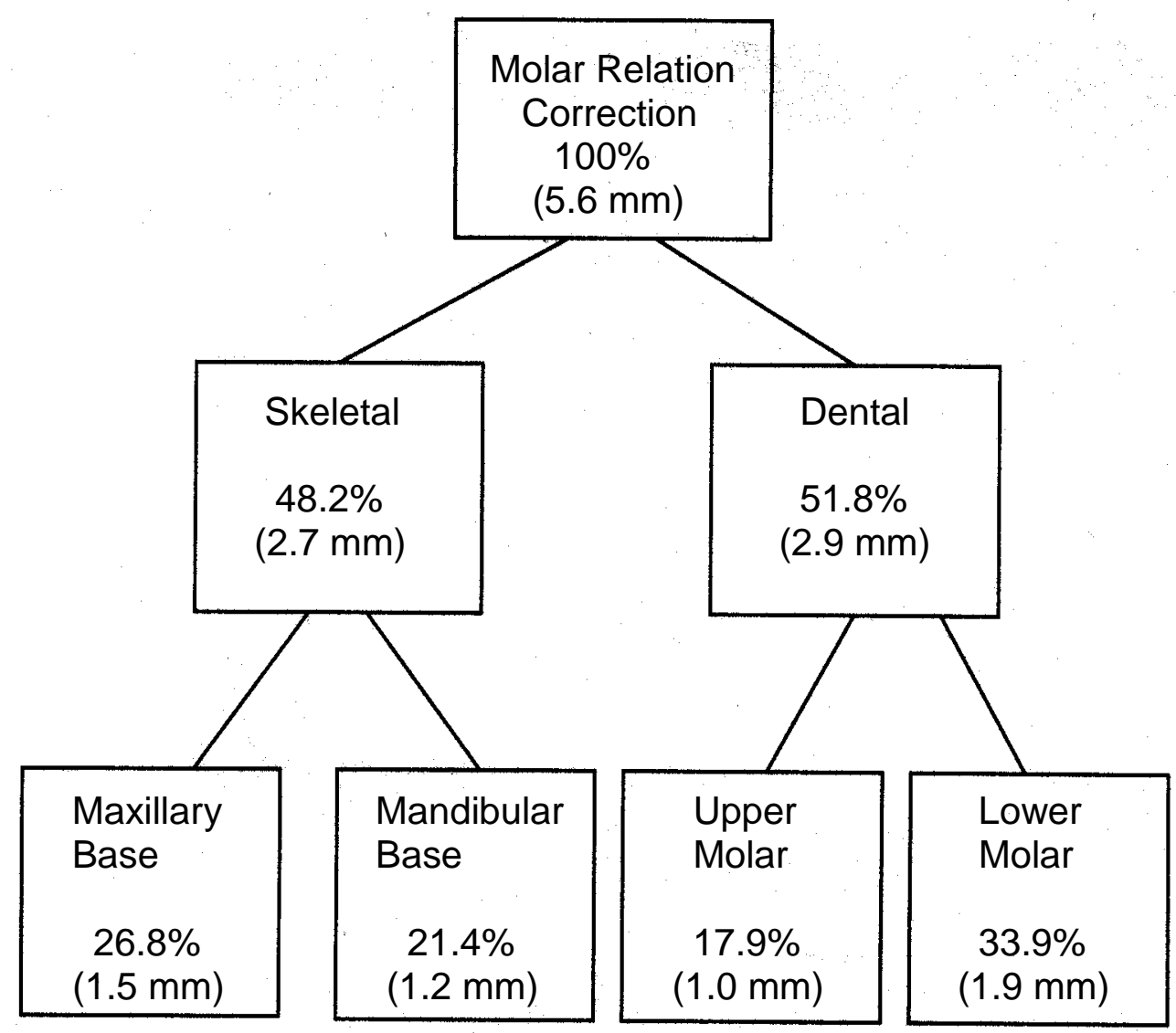

Figure 4. Skeletal and dental contributions to the molar relation correction.

The contribution for the maxillary base, mandibular base, upper molar and lower molar was calculated in the same way. The calculations resulting in this contribution are listed in Table 15. 
Table 15. Molar relationship calculations.

\section{Molar Relationship}

$\begin{array}{llll}\text { Treated Minus } & \text { Control } & (-\mathrm{Mx}) \text { or }(-\mathrm{Md}) & \text { Total }\end{array}$

\section{Skeletal Contribution}

Maxillary Base

Mandibular Base

$-0.4-$

$-1.9$

2.6

$---\quad=$

1.5

3.8

$---\quad=$

1.2

Dental Contribution

\begin{tabular}{|c|c|c|c|c|c|c|}
\hline Upper Molar & 0.5 & - & -2.0 & 1.5 & $=$ & 1.0 \\
\hline Lower Molar & 5.0 & - & 1.9 & 1.2 & $=$ & 1.9 \\
\hline Molar Rel. Correction & 5.7 & - & 0.1 & --- & $=$ & 5.6 \\
\hline
\end{tabular}

* $(-\mathrm{Mx})$ or $(-\mathrm{Md})$ : Maxillary or Mandibular base that needs to be subtracted 


\title{
DISCUSSION
}

\author{
In general, the method of cephalometric analysis by \\ Pancherz used in this study was reliable. The error of all \\ variables was within an acceptable limit for the treatment \\ changes (Table 7).
}

Sagittal changes. Statistical significant differences between the treated and control group were found in 6 of the 8 sagittal variables, as illustrated in Table 11.

Inhibition of maxillary growth relative to the cranial base was found to be statistically significant when compared with the control group at $p<0.05$ (Table 11). The maxilla only came forward an average of $0.4 \mathrm{~mm}$ compared to $1.9 \mathrm{~mm}$ in the control sample, a net restraint of $1.5 \mathrm{~mm}$ of forward growth. A similar headgear effect on the maxilla was also reported by the Wieslander ${ }^{48}$ study. He observed $1.5 \mathrm{~mm}$ of posterior translation of " $A$ " point with a headgear-Herbst Appliance for a period of 5 months. Croft et al observed a $1.2 \mathrm{~mm}$ restraint of the maxilla. He used a crown Herbst for a period of 11 months. Valant and Sinclair ${ }^{53}$ found a lesser headgear effect $(0.7 \mathrm{~mm})$ on the maxilla when a modified removable Herbst Appliance was used in their study. 
Franchi, Bacceti and McNamara ${ }^{64}$ used an acrylic splint Herbst and found a mean increment in total mandibular length of $2.11 \mathrm{~mm}$ when compared with the untreated Class II controls after 28 months. Valant and Sinclair ${ }^{53}$ used a removable modified Herbst appliance, and found an increase in mandibular length of $1.3 \mathrm{~mm}$ over the control group. Although the mandibular length increase was found not to be statistically significant in this study, there was a net increase of $1.2 \mathrm{~mm}$ when compared to the control group.

Dental changes were also found with the bite jumping mechanism produced by the appliance. There was a posteriorly directed force on the upper teeth and an anteriorly directed force on the lower teeth, resulting in distal tooth movement in the maxillary buccal segments and mesial tooth movements in the mandible. This is in agreement with several other published studies. Distal tooth movement $(1.0 \mathrm{~mm})$ of the upper molars was significant $(p<0.01)$. Croft et al ${ }^{7}$ reported a maxillary distal tooth movement of $1.2 \mathrm{~mm}$. The mesial movement of lower molars $(1.9 \mathrm{~mm})$ and incisors $(1.9 \mathrm{~mm})$ were highly significant $(p<0.001)$ when compared to the control group in this study. Valant and Sinclair ${ }^{53}$ reported $1.6 \mathrm{~mm}$ mesial movement of the lower molars using the modified removable 
Herbst. Mesial movement of lower incisor was reported by several investigations: Valant and Sinclair $^{53}$ reported $1.0 \mathrm{~mm}$, Franchi et $a 1^{64}$ reported $1.4 \mathrm{~mm}$ and Pancherz ${ }^{47}$ reported $2.4 \mathrm{~mm}$. The distal movement of upper incisors $(0.0 \mathrm{~mm})$ was not statistically significant at $p<0.05$. This is in agreement with most of the other Herbst studies, Franchi ${ }^{64}$ reported a distal tooth movement of $0.07 \mathrm{~mm}$, Valant and Sinclair ${ }^{53}$ reported 0.2 $\mathrm{mm}$ and Pancher $\mathrm{z}^{47}$ reported a $0.5 \mathrm{~mm}$ distal movement of the upper incisors.

Vertical changes. In Class II patients with a deep bite, Pancherz showed an overbite reduction of $50 \%$ immediately after treatment with the banded Herbst Appliance. ${ }^{54}$ Overbite reduction is mainly accomplished by intrusion of the lower incisors and enhanced eruption of the lower molars in his study. The author pointed out, that part of the vertical incisal changes were a result of proclination of the incisors. As a result, the occlusal plane tips downward. ${ }^{54}$

The overbite reduction in this study was $(p<0.001)$ significantly different between the experimental $(2.5 \mathrm{~mm})$ and the control group $(-0.2 \mathrm{~mm})$, which represents an overbite reduction of $2.7 \mathrm{~mm}$. Lower incisor intrusion of $0.2 \mathrm{~mm}$ was also highly significant $(p<0.001)$ when compared with the 
control group $(-0.8 \mathrm{~mm})$. The eruption of lower molars $(1.1 \mathrm{~mm})$ was not significantly different from the control group $(-0.5 \mathrm{~mm})$. Using the crown Herbst, Croft et a ${ }^{7}$ reported a significant $(\mathrm{p}<0.01)$ overbite correction $(0.6 \mathrm{~mm})$ with a difference of $2 \mathrm{~mm}$ when compared to the control group. Pancherz ${ }^{47}$ using the banded Herbst, reported a $2.5 \mathrm{~mm}$ correction with a difference of $2.6 \mathrm{~mm}$ when compared to the control group. Franchi et $\mathrm{al}^{64}$, Valant and Sinclair ${ }^{53}$ and Windmiller ${ }^{50}$ did not report the changes for overbite correction with the acrylic removable Herbst Appliance.

The mandibular plane angle was not changed significantly when compared to the control group. This could be due to an increase in ramal height during the treatment period as pointed out by McNamara ${ }^{49}$ and Windmiller ${ }^{50}$. The presence of an acrylic bite-block may help in controlling the eruption of molars and hence minimizing the opening of the mandibular plane angle.

The occlusal plane tipped clockwise 1.8 degrees, which was significantly different, compared to the control group $(0.7$ degrees counterclockwise, $p<0.05)$. This is probably related to the differential eruption of the incisors and molars as a result of the treatment and the "bite-plane" effect. 


\begin{abstract}
Although the banded Herbst Appliance has been shown to increase vertical relationships, no change in the nasal plane angle in relation to the cranial base was noted in a study by Franchi et $a l^{64}$. The nasal plane angle in the present study, showed a tipping of 1.4 degrees counterclockwise whereas the control showed a clockwise rotation of 0.4 degrees (Table 11). This is probably due to the headgear effect produced by the appliance.
\end{abstract}

Skeletal and dental contributions to the correction of overjet and molar relationship. The overjet correction in this study improved by $4.6 \mathrm{~mm}$, which was significant at $\mathrm{p}<0.001$. Franchi et $\mathrm{l}^{64}$ observed $3.99 \mathrm{~mm}$ of overjet correction (Acrylic splint Herbst), and Pancherz ${ }^{47}$ found a $5.2 \mathrm{~mm}$ overjet correction (banded Herbst) .

The maxillary base contribution to this change was $32.6 \%$ (1.5 mm) less maxillary length increase, which was significant $(\mathrm{p}<0.05)$. This result that was two times larger $(0.7 \mathrm{~mm})$ than the one found by Valant and Sinclair ${ }^{53}$. However, it was in perfect agreement with the findings reported by Weislander ${ }^{48}$ (1.5 mm), and a similar change was also reported by croft et $a l^{7}(1.2 \mathrm{~mm})$. 
The mandibular base showed an increase in mandibular length of $26.1 \%(1.2 \mathrm{~mm})$, which was not significant at $\mathrm{p}<0.05$. Valant and Sinclair ${ }^{53}$ showed a similar increase in mandibular length when compared to the control group (1.3 mm).

Mesial movement of the lower incisors was found highly significant in this study, representing $41.3 \%(1.9 \mathrm{~mm})$ of the overjet contribution. Pancherz ${ }^{47}$ showed $1.8 \mathrm{~mm}$ of lower incisor mesial movement with the banded Herbst. Franchi et $a l^{64}$ observed 37.3\% (1.7 mm) of incisor mesial movement with acrylic splint Herbst.

Distal movement of upper incisors did not show any significance in this study $0 \%(0.0 \mathrm{~mm})$. Similar results were shown by Franchi et $a I^{64}(0.07 \mathrm{~mm})$, Pancherz ${ }^{47}(0.5 \mathrm{~mm})$, Valant and Sinclair ${ }^{53}(0.2 \mathrm{~mm})$.

The molar relationship correction in this study improved significantly by $5.6 \mathrm{~mm}$. Franchi et al ${ }^{64}$ observed a similar improvement of $5.38 \mathrm{~mm}$. Mesial movement of lower molars was significant, showing $33.9 \%(1.9 \mathrm{~mm})$ of the molar relation correction. Valant and Sinclair ${ }^{53}$, on the other hand, reported 
$1.6 \mathrm{~mm}$ mesial movement of the lower molars when the modified removable Herbst was used.

Distal movement of the upper molar was significant $(\mathrm{p}<0.01)$ showing $17.9 \%$ of the molar relation correction $(1.0 \mathrm{~mm})$. Croft et $a \mathrm{I}^{7}$ reported a $1.2 \mathrm{~mm}$ of molar distal movement using the crown Herbst whereas Valant and Sinclair ${ }^{53}$ obtained $1.5 \mathrm{~mm}$ using the modified removable Herbst.

Franchi et $a 1^{64}$ reported that there is a greater skeletal contribution to the correction of both overjet and molar relation in subjects treated with the acrylic splint Herbst when compared with the results reported by Pancherz for a 6 month period of active treatment with the banded Herbst appliance. According to Franchi this is due to the smaller effect on the maxillary dentition and, more specifically to the minimal treatment effects on maxillary skeletal structures. This study did not show a lesser amount of dentoalveolar changes as a result of using the acrylic splint Herbst appliance. This is probably due to the significant headgear effect showed in this study.

The lower splint presumably helps to avoid proclination of lower incisors, although in this study the mesial movement 
was significant. Franchi et $a 1^{64}$ showed that the mesial movement of the mandibular dentition represented the only significant dental change, and this movement contributed to the correction of both overjet and molar relation.

\section{Clinical Implications}

1. The acrylic Herbst with removable lower member has similar effects as the fixed Herbst.

2. For the overjet correction: the skeletal contribution was of $58.7 \%$, and the dental contribution was of $41.3 \%$.

3. For the molar correction: the skeletal contribution was of $48.2 \%$, and the dental contribution was of $51.8 \%$.

4. Because the acrylic Herbst Appliance has the advantage of a removable lower member, oral hygiene is easier to attain for the patient.

5. Since more teeth are anchored with the Acrylic splint Herbst Appliance breakage is less likely to occur when compared to the other designs of the Herbst Appliance.

\section{Future Studies}

Other investigators have reported that there is a greater skeletal contribution in subjects treated with the acrylic splint Herbst when compared with the results reported with fixed Herbst Appliance. The results presented here, shows that 
the acrylic splint Herbst Appliance has similar effects as the ones shown with the fixed Herbst Appliance. Further studies with longer-term effects, will be needed to corroborate these findings. 


\section{CHAPTER V \\ SUMMARY AND CONCLUSION}

$\underline{\text { SUMMARY }}$

The propose of this study was to determine the amount of skeletal and dental cephalometric changes of Class II patients treated with acrylic splint Herbst appliance.

The sample consisted of one experimental group and one control group. The experimental group consisted of lateral cephalometric radiographs of 22 patients who have been treated with acrylic splint Herbst from the files of the Department of Orthodontics, School of Dentistry, West Virginia University . The control group consisted of 22 cephalometric radiographs of Class II patients with no treatment, selected form the Case Western University Bolton-Brush Study, Cleveland Ohio. These patients were matched in sex, age and craniofacial morphology with the experimental group subjects.

The cephalometric system described by Pancherz ${ }^{47}$ was used in this study. An analysis of variance (ANOVA) was used to determine statistical significant differences.

The following hypotheses were to be tested at the completion of this research: 
1. There are no significant skeletal changes using cephalometric linear and angular measurements in patients treated with the acrylic splint Herbst appliance when compared with the control group.

2. There are no significant dental changes using cephalometric linear and angular measurements in patients treated with the acrylic splint Herbst appliance when compared to the control group.

\section{CONCLUSIONS}

Six conclusions have resulted from this study. The first two conclusions address the hypotheses tested in this study. The remaining, conclusions are divided in two sections. The first section addresses the sagittal dimension (\#' 3 and 4), and the second section addresses the vertical dimension (\#'s 5 and 6).

1. Statistical significant differences in skeletal changes were found in patients treated with the acrylic splint Herbst when compared with the control group. 
2. Statistical significant differences in dental changes were found in patients treated with the acrylic splint Herbst when compared with the control group.

In the sagittal dimension:

3. In the skeletal region the inhibition of maxillary growth relative to the cranial base was found to be significant (headgear effect). A mandibular length increase of $1.2 \mathrm{~mm}$ when compared to the control group was found.

4. In the dentoalveolar region all the sagittal changes towards the correction of the Class II relationship were significant (lower incisor, overjet, upper and lower molars, and molar relationship), with the exception of distal movement of the upper incisor.

In the vertical dimension:

5. In the skeletal region the clockwise rotation of the nasal plane angle was statistically significant. Whereas the mandibular plane angle did not change significantly, probably the result of an increase in 
ramus height. No significant changes were found in the maxillary base and lower facial height.

6. In the dentoalveolar region the overbite reduction and lower incisor intrusion was significant. The clockwise rotation of the occlusal plane angle was also significant. No significant changes were found for the upper incisors, upper molars and lower molars. 


\section{REFERENCES}

1. McNamara JA Jr, Howe RP. Clinical management of the acrylic splint Herbst appliance. Am J Orthod Dentofacial Orthop 1988; 94:142-149.

2. McNamara Ja. Jr., Ellis E. Cephalometric analysis of untreated adults with ideal facial and occlusal relationships. Int $J$ Adult Orthodont Oral Surg 1988; $3: 221-231$.

3. Proffit WR, Fields HW. Contemporary Orthodontics, $2^{\text {nd }}$ edition. St. Louis: Mosby Year Book, 1993.

4. Dixon A.D., Hoyte D.A., Ronning O. Fundamentals of Craniofacial Growth. Boca Raton: CRC Press, 1997

5. Pancherz H. The Herbst appliance-Its biologic effects and clinical use. Am J Orthod 1985;87:1-20.

6. Pancherz H, Hagg U. Dentofacial orthopedics in relation to somatic maturation. An analysis of 70 consecutive cases treated with the Herbst appliance. Am J Orthod 985;88:273287 .

7. Croft R, Buschang P, English J, Meyer R. A cephalometric and tomographic evaluation of Herbst treatment in the mixed dentition. Am $J$ Orthod and Dentofacial Orthop. $1999 ; 116: 435-443$.

8. Paulsen HU, Karle A, Bakke M. Herskind A. CT scanning and radiographic analysis of temporomandibular joints and cephalometric analysis in a case of Herbst treatment in late puberty. Eur J Orthod 1995;17:165-75.

9. Kelly JE, Sanchez M, Van Kirk LE. An assessment of the occlusion of the teeth of children. DHEW Publication No (HRA) 74-1612, Washington, DC: National Center for Health Statistics, 1973.

10. Kelly JE, Harvey C. An assessment of the teeth of youths 12-17 years, DHEW Publication No (HRA) 77-1644, Washington, DC: National Center for Health Statistics, 1977 . 
11. McLain JB, Steedle JR, Vig PS. Face height and dental relationships in 1600 children: A survey. J Dent Res $1983 ; 62: 308$.

12. McLain JB, Proffit WR. Oral health status in the United States: Prevalence of Malocclusion.J Dent Educ 1985;49: 386-396.

13. Henry RG. A classification of Class II, division 1 malocclusion. Angle of Orthod 1957;27:83-92.

14. Moyers RE, Riolo ML, Guire KE, et al. Differential diagnosis of Class II malocclusions:Part I-Facial types associated with Class II malocclusions. Am J Orthod $1980 ; 78: 477-494$.

15. MCNamara JA Jr. Components of Class II malocclusion in children 8-10 years of age. Angle of Orthod 1981;51:177202 .

16. Drelich RC.A cephalometric study of untreated Class II, division 1 malocclusion. Angle Orthod 1948;18:70-75.

17. Nelson WE, Highley LB. Length of mandibular basal bone in normal occlusion and Class I malocclusion compared to Class II, division 1 malocclusion. Am J Orthod 1948; $34: 610-617$.

18. Renfroe EW. A study of the facial patterns associated with Class I, Class II, division 1 and Class II division 2 malocclusions. Angle Orthod 1948;19:12-15.

19. Gilmore WA. Morphology of the adult mandible in Class II division 1, malocclusion and in excellent occlusion. Angle Orthod 1950;20:137-146.

20. Craig CE. The skeletal patterns characteristic of Class I and Class II, division 1 malocclusions, in normal lateralis. Angle Orthod 1951;21:44-56.

21. Riedel RA. The relationship of maxillary structures to cranium in malocclusion and normal occlusion. Angle Orthod $1952 ; 22: 142-145$. 
22. Blair ES. A cephalometric roentgenographic appraisal of the skeletal morphology of Class I, Class II, division 1 and Class II, division 2 (angle) malocclusion. Angle Orthod $1954 ; 24: 106-119$.

23. Altemus LA. Horizontal and vertical dentofacial relationships in normal and Class II, division 1 malocclusions in girls 11-15 years. Angle Orthod $1955 ; 25: 120-137$.

24. Hunter WS. The vertical dimensions of the face and skeletodental retrognathism. Am J Orthod 1967;53:586- 595.

25. Rothstein TI. Facial morphology and growth from 10-14 years of age in children presenting Class II, division 1 malocclusion: A comparative roentgenographic cephalometric study. Am J Orthod 1971;60:619-629.

26. Hitchcock HP. A cephalometric description of Class II, division 1, malocclusion. Am J Orthod 1973;63:414-423.

27. Carter NE. Dentofacial changes in untreated Class II, division 1 subjects. Brit J Orthod 1987;14:225-234.

28. Enlow DH, Facial Growth, $3^{\text {rd }}$ edition, 1990, WB Saunders Company.

29. Ngan PW, Byczek E, Scheick. Longitudinal Evaluation of growth changes in Class II division 1 subjects, Seminars in Orthodontics 3:4 December 1997, p.222-231.

30. Bjork A. Variations in the growth pattern of the human mandible: Longitudinal radiographic study by the implant method. J Dent Res 1963;42: 400-411.

31. McNamara JA., Peterson JE., Alexander RG. ThreeDimensional diagnosis and management of Class II malocclusion in the mixed dentition. Seminars in Orthodontics, 2:2 June, 1996: pp. 114-137. 
32. MCNamara JA Jr, Burst EW, Riolo ML. Soft tissue evaluation of individuals with an ideal occlusion and a well-balanced face. In: McNamara JA. Jr, editor. Esthetics and the treatment of the facial form. Monograph 28, Craniofacial Growth Series, The University of Michigan, Ann Arbor: Center for Human Growth and Development, 1989.

33. McNamara JA Jr. A method of cephalometric evaluation. Am J Orthod 1984;86:449-469.

34. Reidel RA. The relation of maxillary structures to cranium in malocclusion and in normal occlusion. Angle orthod $1952 ; 22: 142-145$.

35. Steiner CC. Cephalometric for you and me. Am J Orthod $1953 ; 39: 729-755$.

36. Mcnamara JA Jr, Brudon WL. Orthodontic and Orthopedic Treatment in the Mixed Dentition. Ann Arbor: Needham Press, 1993.

37. Ricketts RM. The influence of the orthodontic treatment on facial growth and development. Angle Orthod 1960; 30:103133 .

38. Schudy FF. Vertical growth versus antero-posterior growth as related to function and treatment. Angle orthod $1964 ; 75-93$.

39. Schudy FF. The rotation of the mandible resulting from growth: Its implications in orthodontic treatment. Angle Orthod $1965 ; 35: 36-50$

40. Tollaro I, Baccetti T, Franchi L, et al. Interarch transverse discrepancy in Class II malocclusion during the mixed dentition. Am J Orthod Dentofacial Orthop 1996.

41. Baccetti T, Franchi L, McNamara JA Jr, et al. Early dentofacial features of Class II malocclusion: A longitudinal study from the deciduous through the mixed dentition. Am J Orthod Dentofacial Orthop 1996

42. Arya BS, Savara BS, Thomas DR. Prediction of $1^{\text {st }}$ molar occlusion. Am J Orthod '1973;63:610-621.

43. Bishara SE, Hoppens BJ, Jakobsen JR, et al. Changes in the molar relationship between the deciduous and permanent 
dentitions: A longitudinal study. Am J Orthod Dentofacial Orthop 1988;93:19-28.

44. Spillane LM, MCNamara JA Jr. Maxillary adaptations following expansion in the mixed dentition. Semin orthod $1995 ; 1: 176-187$.

45. Gianelly A.A., A Strategy for nonextraction Class II Treatment. Semin Othod 1998;4:1, 26-32.

46. Moore R.N., Principles of Dentofacial Orthopedics. Semi Orthod 1997;3:4 212-221.

47. Pancherz H. Treatment of Class II malocclusions by jumping the bite with the Herbst appliance. A cephalometric investigation. Am J Orthod 1979;76:423-442.

48. Wieslander L. Intensive treatment of severe Class II malocclusion with a Headgear-Herbst appliance in the early mixed dentition. Am J Orthod 1984;86:1-13.

49. McNamara JA, Jr, Howe RP, Dischinger TG. A comparison of the Herbst and Frankel appliances in the treatment of Class II malocclusion. Am J Orthod Dentofacial Orthop $1990 ; 98: 134-144$.

50. Windmiller EC. The acrylic-splint Herbst appliance: A cephalometric Evaluation. Am J Orthod Dentofacial Orthop $1993 ; 104: 73-84$.

51. Goodman P, McKenna P. Modified for the mixed dentition. J Clinc Orthod 1985;19:811-814.

52. Dischinger TG. Edgewise bioprogresive Herbst appliance. J Clin Orthod 1989;23:608-617.

53. Valant JR, Sinclair PM. Treatment effects of the Herbst appliance. Am J Orthod Dentofacial Orthop.1989;95:138-147.

54. Pancherz H. The effect of continuous bite jumping on the dentofacial complex: A follow up study after Herbst appliance treatment of Class II malocclusions. Eur $\mathrm{J}$ Orthod $1981 ; 3: 49-60$.

55. Bakke M. Paulsen HU. Herbst treatment in late adolescence: clinical, electromyographic, kinesiographic, and 
radiographic analysis of one case. Eur J Orthod $1989 ; 11: 397-407$.

56. Wieslander L. Long-term effect of treatment with the headgear-Herbst appliance in the early mixed dentition. Stability or Relapse? Am J Orthod Dentofacial Orthop $1993 ; 104: 319-329$.

57. Schiavoni R, Grenga V, Macri V. Treatment of Class II high angle malocclusions with the Herbst appliance: a cephalometric Investigation. Am J Orthod Dentofacial Orthop 1992;102:393-409.

58. Pancherz $H$. the Effects, Limitations, and Long-term Dentofacial Adaptations to Treatment with the Herbst Appliance, Seminar in Orthodontics 3:4 December $1997 \mathrm{pp}$. 232-243.

59. Pancherz H. The mechanism of Class II correction in Herbst appliance treatment, a cepahalometric investigation. Am J Orthod 1982;82:107-113.

60. Dischinger T. Edgewise Herbst Appliance.J Clin Orthod 1995; 29:738-742.

61. Rudzki-Janson and Noachtar.Functional Appliance Therapy with the Bionator, Seminar in Orthodontics, 4:1 March, 1998: pp.33-45.

62. McNamara.Fabrication of the acrylic splint Herbst appliance. Am J Orthod Dentofac. Orthop 1988;94:10-18

63. Lai M, McNamara JA, Jr. An Evaluation of two-phase Treatment with the Herbst Appliance and Preadjusted Edgewise Therapy. Seminar in Orthodontics, 1998;4:46-58.

64. Franchi L, Baccetti T, McNamara JA, Jr. Treatment and Posttreatment effects of acrylic splint Herbst appliance therapy. Am J Orthod Dentofacial Orthop. 1999;115:429-438.

65. Ngan P., Hagg U., Yiu C., Merwin D., and Wei S. Treatment response to maxillary expansion and protraction. Euro J Orthod. !996; 18:151-168. 
APPENDIX A

IRB Approval 


\section{Application for Exemption}

You must receive approval from the IRB staff prior to beginning the research described below. Please type all responses and submit this form with original signatures.

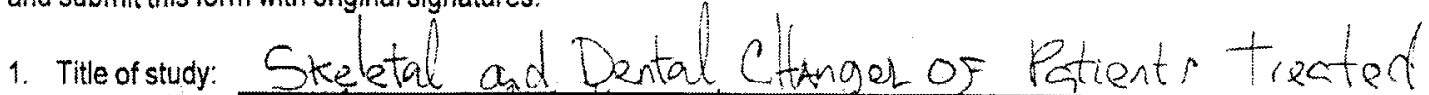

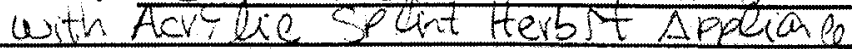

2. Investigators (list all investigators, principal investjgator first; attach additional sheets if necessary):

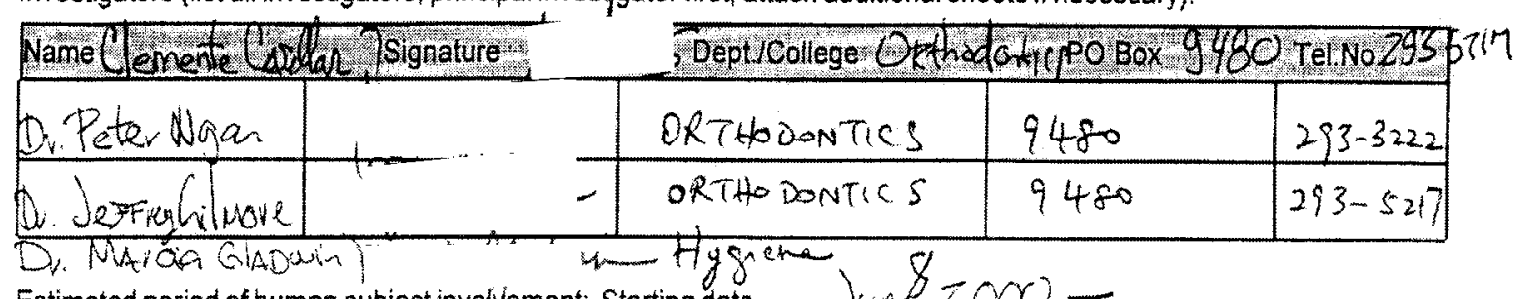

3. Estimated period of human subject involvement: Starting date sune $(000$

4. Reasonfor conducting research

$\square$ Professional $\square$ Class Assignment QDissertation DThesis Oother

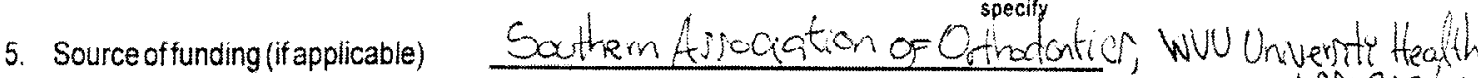
Arociatel

6. This research involves (check all that apply-see attached "Exempt Research" page)

a. collection or study of existing data, documents, records or specimens, recorded without identifiers

_b. normal educational practices conducted in established or commonly accepted educational settings

C. educational tests (cognitive, diagnostic, aptitude, achievement)

- d. observation of public behavior

- e. surveys, interviews or hand-outs for subjects over 18 (use age ranges, not actual age, for demographit information): Qmail $\quad$ Qtelephone

f. any possibility of identifying a subject (discuss in cover letter)

_ 9. the possibility that the subject's responses or conduct (if they became public) may place the subject at risk of criminal or civil liability or be damaging to the subject's financial standing or employability

_h. sensitive aspects of personal behavior (for example: illegal conduct, drug use, sexual behavior or use of alcohol)

_. investigator's participation in activities being observed

-1. Only surveys or interviews of elected or appointed public officials or candidates for public office

- $k$. audiotaping

-1. children under age 18 (see Chapter Il of the Guidelines)

Note: Interviews and surveys with children areneverexempt.

_m. food tasting and evaluation

n. research and demonstration projects

7. Goalofresearcin

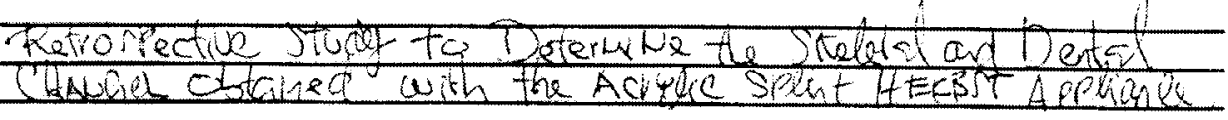


8. Explanation of procedures involved in research

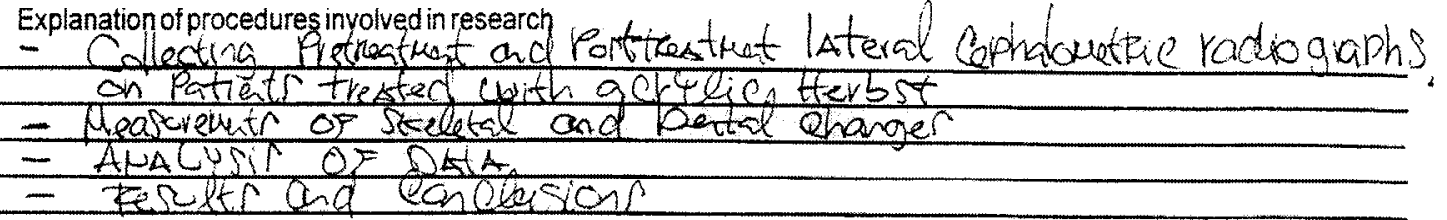

9. Explanation of known risks to human subjects

None

10. Explanation of how records will be kept

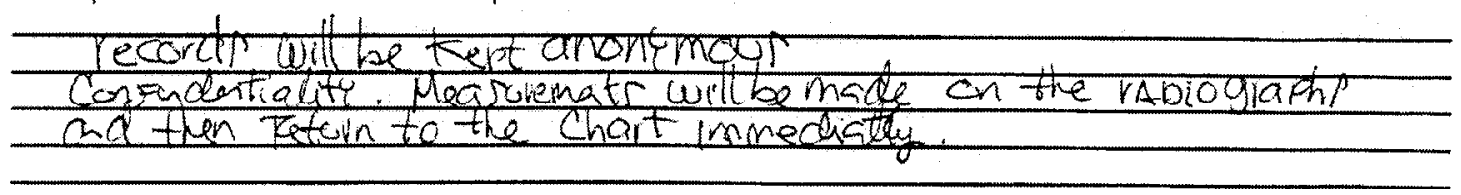

A cover letter addressed to respondents must accompany any survey or questionnaire. The cover letter must be on your WU departmental letterhead and must include the following:

1. a statement that the project is research being conducted in partial fulfilment of the requirements for a course, master's thesis, dissertation, etc.

2. purpose of study

3. a statement that subjects' responses will be kept anonymous or confidential (explain extent of confidentiality if subjects' names are requesied)

4. if audiotaping, a statement that subject is being audiotaped (explain how tapes will be stored or disposed of during and after the study)

5. a statement that subjects do not have to answer every question

6. a statement that subject's class standing, grades, or job status (or status on an athletic team, if applicable) will not be affected by refusal to participate or by withdrawal from the study

7. a statement that participation is voluntary

Attachments:

- questionnaire/survey to be used

_telephone text (including introductory remarks as in a cover letter-see above)

$\checkmark$ coverletter

_ permission from externalinstitution, on their letterhead (if applicable)

Ihave reviewed the above information and recommend this study for exemption.
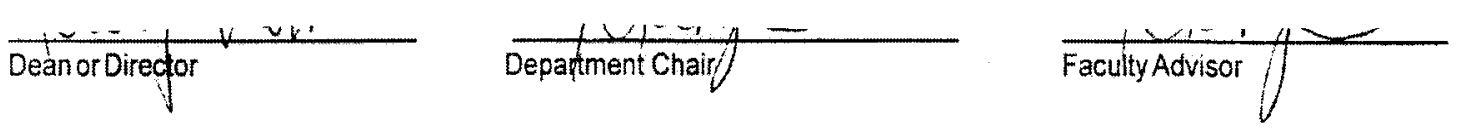


\section{VITA}

\section{Personal Data}

Name: Jorge Clemente Casellas Galvez

Date of birth: January 23, 1972

Place of birth: Guatemala

\section{Education}

Orthodontic School: West Virginia University,West Virginia (1998-2001) M.S. Dental School: Francisco Marroquin University,Guatemala (1994-1998) D.D.S College: Francisco Marroquin University,Guatemala (1990-1993) B.S.

\section{Scholastic Research}

Thesis (graduation requirement for the degree of Master of Sciences in Orthodontics) Skeletal and dental changes with the acrylic splint Herbst Appliance (2001).

Thesis (graduation requirement for Dental School): Epidemiology of class III malocclusion in Guatemala City. (1997)

\section{Professional Organizations:}

American Association of Orthodontics (AAO), 1999

South Association of Orthodontics (SAO), 1999 